THE TIME-VARYING NAIRU AND ITS

IMPLICATIONS FOR ECONOMIC POLICY

Robert J. Gordon

Working Paper 5735

\author{
NATIONAL BUREAU OF ECONOMIC RESEARCH \\ 1050 Massachusetts Avenue \\ Cambridge, MA 02138 \\ August 1996
}

This research is supported by the National Science Foundation. I am grateful to Tomonori Ishikawa for research assistance and to Mark Watson for helpful discussions. This paper is part of NBER's research program in Economic Fluctuations and Growth. Any opinions expressed are those of the author and not those of the National Bureau of Economic Research.

(C) 1996 by Robert J. Gordon. All rights reserved. Short sections of text, not to exceed two paragraphs, may be quoted without explicit permission provided that full credit, including $\mathbb{C}$ notice, is given to the source. 


\title{
THE TIME-VARYING NAIRU AND ITS \\ IMPLICATIONS FOR ECONOMIC POLICY
}

\begin{abstract}
$\underline{\text { ABSTRACT }}$

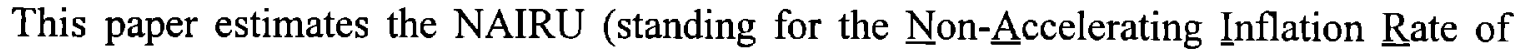
Unemployment) as a parameter that varies over time. The NAIRU is the unemployment rate that is consistent with a constant rate of inflation. Its value is determined in an econometric model in which the inflation rate depends on its own past values ("inertia"), demand shocks proxied by the difference between the actual unemployment rate and the estimated NAIRU, and a set of supply shock variables.

The estimated NAIRU for the U.S. economy differs somewhat for alternative measures of the inflation rate. The NAIRU estimated for the GDP deflator varies over the past forty years within the narrow range of 5.7 to 6.4 percent; its estimated value for the most recent quarter (1996:Q1) is 5.7 percent. In that quarter a lower NAIRU of 5.3 percent is obtained for the chain-weighted PCE deflator. Recent research claiming that there is a three-percentage-point range of uncertainty about the NAIRU is rejected as inconsistent with the behavior of the American economy in the late 1980s and early 1990 s.
\end{abstract}

Robert J. Gordon Department of Economics Northwestern University Evanston, IL 60208-2600 and NBER rjg@merle.acns.nwu.edu 
The relationship between inflation and unemployment is central to the conduct of monetary policy. More than 35 years ago Paul Samuelson and Robert Solow (1960) coined the term "Phillips curve" at the 1959 AEA meetings, reacting promptly to the publication of Phillips's seminal (1958) article. A few years later Milton Friedman (1968) coined the term "natural rate of unemployment," which more recently has come to be known by the familiar

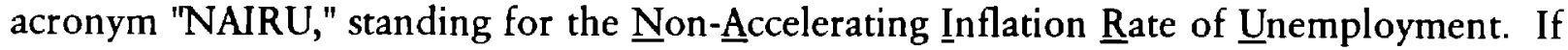
at any given time there exists a unique NAIRU, then the Phillips curve tradeoff is vertical at that unemployment rate. The Fed cannot make the actual unemployment rate differ from the NAIRU in the long run, but it can maintain a stable rate of inflation if it succeeds in setting the actual unemployment rate equal to the NAIRU. If instead of maintaining a stable rate of inflation, the Fed desires to reduce the inflation rate toward zero or some other target, then it needs to keep the actual unemployment rate above the NAIRU. Either way, whether the goal is steady inflation or lower inflation, the Fed needs to know the value of the NAIRU.

The NAIRU is not carved in stone. In Friedman's (1968) interpretation, the NAIRU is "ground out" by the set of "Walrasian" microeconomic relations in the economy, including the structure and institutions of product and labor markets, and any of these relations can change. There is a perception that much about the economy has changed in the 1990s, and if so the NAIRU has doubtless changed as well. Indeed, as we shall see, the NAIRU has exhibited pronounced cycles over the postwar period, albeit within a surprisingly narrow range.

The Fed acts as if it already accepts the fact that the NAIRU can move and has adapted policy procedures that implicitly incorporate new information to update previous 
estimates of the NAIRU. Whereas in early 1994 it implicitly believed that the NAIRU was around 6.0 percent and sharply raised short-term interest rates when it correctly predicted that the actual unemployment rate was about to fall below 6.0 percent, for most of 1995 and early 1996 it allowed short-term interest rates to drift down slightly when inflation did not accelerate in response to an average unemployment rate well below 6.0 percent. $^{1}$

For many years it was reasonable to assume that the NAIRU was 6.0 percent, and I tested that assumption repeatedly by running dynamic simulations of regression equations that predict the value of the inflation rate. ${ }^{2}$ Because these simulations were capable of tracking the inflation rate accurately for many years after the end of the regression sample period, e.g., 1987-94, without any appreciable drift, I had submitted the accuracy of such post-sample simulations as evidence that the NAIRU was still 6.0 percent. The substantial acceleration of inflation that occurred in 1988-89, when the unemployment rate fell below 6.0 percent for a period of three years, is consistent with the view that the NAIRU was at 6.0 percent or above as recently as $1988-89$.

1. Even though the actual unemployment rate averaged 5.6 percent in the 21 months ending in May, 1996, below the Fed's previous NAIRU estimate of 6.0 percent, the inflation rate did not accelerate. Indeed, one key measure of inflation, the personal consumption deflator (on the new chain-weighted basis) decelerated.The implicit price deflator for personal consumption expenditures on the new chain-weighted basis rose 2.7 percent in 1992, 2.6 percent in 1993, 2.4 percent in 1994, 2.4 percent in 1995, and only 1.9 percent in the four quarters ending in 1996:Q1.

2. The inflation equation was developed in a series of papers, including Gordon (1970, 1975, 1977a, and 1982b). King-Watson (1994) have called this approach the "Gordon-Solow model," citing the first of my papers and Solow's 1969 book. In order to determine whether the inflation relationship has changed, I have maintained unchanged the set of variables, lag lengths, and other features of the equation introduced in Gordon (1982b) and Gordon-King (1982). The most recent assessments of the performance of this equation are contained in Gordon (1990a, 1994). 


\section{The Time-Varying NAIRU, Page 3}

However, numerous factors have changed since 1988-89 in a way that may have reduced the NAIRU, and indeed the absence of an acceleration of inflation in 1995-96 suggests that the NAIRU may well have fallen below 6.0 percent. Labor unions are weak and their penetration in the labor force continues to decline. Manufacturers have been under intense pressure from consumers and foreign competitors to restrain price increases. The rest of the industrial world has experienced a sluggish recovery, and there is ample foreign capacity to provide supplies to U. S. manufacturers. Business executives are quoted as arguing that the economy has changed drastically in the last ten years. General Electric's John F. Welch Jr. recently stated that "There is no inflation . . . there is no pricing power at all" (Stevenson, 1996).

\section{The "Quiescence" of Phillips Curve Research}

Has the NAIRU declined? If so, from what level a decade ago to what level today? Surprisingly, macroeconomists have thus far provided no answer to this question that can be taken "off the shelf" by policymakers who need to know the answer. For remarkably little research has been conducted on the U.S. inflation process in the past decade, in contrast to feverish research activity in the 1960s and 1970s. King-Watson (1994) comment on the "quiescence" of the field. One explanation of this void is that the U. S. inflation process is so stable, and the models developed in the early 1980 s work so well, that there have been no behavioral mysteries to solve. In the words of King and Watson, "Keynesian economists" have continued to view the Phillips curve as an essentially intact structural relation, once the original econometric models of the 1960 s were amended "to represent 
supply shocks and build in a zero long-run tradeoff" $(1994$, p. 160). Once this task had been accomplished (as in Gordon, 1977), there was no further agenda warranting continued research, except periodically checking that the relation remained stable, and indeed "the remarkable feature of the Phillips curve in the post war period was its stability" (WatsonKing, 1994, p. 160).

In this interpretation, macroeconomics has split into two camps. Across the street from the Keynesians are the "neoclassical and monetarist economists." They (notably LucasSargent 1978) dismissed the Phillips curve as "econometric failure on a grand scale," since the long-run negative correlation between inflation and unemployment predicted by the models of the late 1960 s contrasted with the distinctly positive correlation in the data of the 1970s. At that point neoclassical economists stopped paying attention to empirical work on the Phillips correlation and did not notice, much less take seriously, the resurrection of a new breed of post-1975 Phillips curve estimates that incorporated a vertical long-run tradeoff and included supply-shock variables that allowed the model to generate either a negative or positive correlation between inflation and unemployment, depending on whether the economy was subjected to demand or supply shocks.

Instead of taking inflation as the variable to be determined by their models, neoclassical economists turned to real theories of aggregate fluctuations in which the behavior of inflation was neither explored nor explained. While real output was determined by the set of behavioral equations in the model (whether of the Lucas "surprise" or realbusiness-cycle variety), the determination of the price level was left unspecified. Implicitly, 
the price level was left as a residual, i.e., as the level of nominal GDP (in turn often equal to the money supply plus a stochastic error term) divided by whatever level of real GDP was determined by the model. This treatment was the diametric opposite to that implied in the Phillips curve approach, in which an equation is specified to determine the inflation rate, while the growth rate of real GDP is implicitly a residual equal to the rate of nominal GDP growth minus the rate of inflation.

\section{Agenda for this Paper}

The NAIRU is defined as the unemployment rate consistent with steady inflation under a specified set of conditions. It is meaningful only within a well-specified model of the inflation process. This paper begins by describing the mainstream "triangle model" of the inflation process that incorporated and resurrected the Phillips curve from what Lucas and Sargent (1978) had called the "wreckage" of the early and mid 1970s. We define the NAIRU in terms of this model and examine both what the model includes (e.g., supply shocks and rate of change effects) and what it excludes (any explicit role for expectations or wages).

Then, instead of simply assuming a value for the NAIRU and testing the validity of that assumed value in dynamic post-sample simulations, this paper adapts an explicit econometric technique that allows a time-varying NAIRU to be estimated. We show intituitively why some previous authors, notably Staiger $e t$. al. (1996), have found estimates of the NAIRU to be highly imprecise, and we propose a simple criterion to clear the cloud of ambiguity which surrounds the topic. We emerge with a set of alternative NAIRU 
estimates for the 1955-96 period which differ only moderately from each other depending on which inflation measure, specification, and sample period is used.

As we shall see, the most interesting differences among the proposed NAIRU series for the current period relate to the contrasting behavior of alternative price indexes, and we suggest that the Fed needs to decide which inflation index it is trying to stabilize, e.g., the GDP deflator, the deflator for Personal Consumption Expenditures (PCE), or the Consumer Price Index. After we identify the alternative NAIRU series, we then use preferred versions of the inflation equation to compute dynamic simulations of the inflation rate in future years on the assumption of alternative paths for the actual unemployment rate. The paper concludes by examining implications for the past, current, and future conduct of monetary policy.

Several important topics lie outside of the research agenda in this paper. First, it is entirely concerned with the inflation process in the United States and does not treat the quite different behavior of inflation and unemployment in Europe or Japan. Second, it estimates the time-varying NAIRU within the context of the "triangle" model of the inflation process developed in my previous work; it does not develop such a model from scratch. Third, it asks which unemployment rate should be the Fed's target but does not inquire into the methods by which the Fed should attempt to accomplish that goal, i.e., it does not study the channels of monetary policy that link changes in the short-term interest rate to subsequent lagged responses of output, income, employment, and unemployment.

To preview the main conclusions, at any given time there is a NAIRU for the U. S. 


\section{The Time-Varying NAIRU, Page 7}

economy. Our alternative NAIRU estimates differ moderately among among themselves regarding the exact level of the 1996 NAIRU, depending primarily on the inflation index to be used. The alternative estimates all support the conclusion that the NAIRU has declined substantially since $1988-89$, opening up the opportunity for the Fed to maintain a lower unemployment rate than was feasible then. Further, the time-varying NAIRU provides a marginally better explanation of inflation behavior in the 1990s than the previously assumed fixed NAIRU of 6.0 percent.

\section{The "Triangle" Model of Inflation}

The "Phillips curve" has become a generic term for any relationship between the rate of change of a nominal price or wage and the level of a real indicator of the intensity of demand in the economy, such as the unemployment rate. Long ago, the simple Phillips relation was amended by incorporating supply shocks and a zero long-run tradeoff. ${ }^{3}$ What emerged was an interpretation of the Phillips curve that I have called the "triangle" model of inflation - a label summarizing the dependence of the inflation rate on a tripartite set of basic determinants: inertia, demand, and supply.

In this framework a general specification for the rate of price change $\left(p_{t}\right)$ is:

$$
p_{t}=a(L) p_{t-1}+b(L) D_{t}+c(L) z_{t}+e_{t}
$$

Here lower-case letters designate first differences of logarithms, upper-case letters

3. Schultze (1975) and Gordon (1975) introduced explicit variables to isolate the effect of food and energy prices and price controls on the U. S. inflation rate. 


\section{The Time-Varying NAIRU, Page 8}

designate logarithms of levels, $L$ is a polynomial in the lag operator, $D_{t}$ is an index of excess demand (normalized so that $D_{t}=0$ indicates the absence of excess demand), $z_{t}$ is a vector of supply shock variables (normalized so that $z_{t}=0$ indicates an absence of supply shocks), and $e_{t}$ is a serially uncorrelated error term. The "triangle" rubric is associated with the three sets of basic determinants, respectively "inertia" (i.e., the influence of the lagged inflation terms), demand (the $D_{t}$ terms), and supply (the $z_{t}$ terms).

If the sum of coefficients on lagged inflation equals unity $\left(\Sigma a_{i}=1\right)$, then there is a "natural rate" of the demand variable $\left(D^{N}\right)$ consistent with a constant rate of inflation. While the estimated sum of coefficients on lagged inflation is usually roughly equal to unity (see Tables 1-3 below), that sum must be constrained to be exactly unity for a meaningful natural rate of the demand variable to be calculated from (1). Among the demand variables that have been entered as proxies for $D_{t}$ are the "output gap" (log ratio of actual to natural or potential real GDP), the "unemployment gap" (difference between the actual and natural rate of unemployment - or NAIRU), and the rate of capacity utilization.

As written in (1) the model is incomplete, even if the supply shock variables $\left(z_{t}\right)$ are exogenous, since there are two endogenous variables, the inflation rate $\left(p_{t}\right)$ and the demand variable $\left(D_{t}\right)$. The model can be closed with one or more equations specifying the demand process. The simplest approach defines $D_{t}$ as the $\log$ output ratio $\left(R_{t}=\ln \left(Y_{t} / Y^{N}{ }_{t}\right)\right)$ or "output gap," treats as exogenous the growth rate of nominal GDP in excess of natural output growth ("excess nominal GDP growth"), and closes the model with a second equation which is simply an identity relating the change in the output gap to inflation and excess 
nominal GDP growth. This identity, used in one form or another in many macroeconomics textbooks, states that the change in the output gap equals the growth rate in nominal GDP $\left(x_{t}\right)$ relative to natural output growth $\left(y_{t}^{*}\right)$, minus the inflation rate:

$$
R_{t}-R_{t-1} \equiv x_{t}-y_{t}^{*}-p_{t} .
$$

The model consisting of (1) and (2) has two equations in two unknowns, $R_{t}$ and $p_{t}$. The exogenous demand shock variable is excess nominal GDP growth $\left(x_{t}-y^{*}{ }_{t}\right)$, the exogenous supply shock variable is the vector $z_{t}$, and the lagged elements $p_{t-1}$ and $R_{t-1}$ are predetermined in previous time periods.

\section{Interpretations of the NAIRU}

In this paper we are interested in estimating the NAIRU, i.e., the unemployment rate that is consistent with steady inflation. The equations estimated in this paper are identical to (1) with the unemployment gap substituted for $D_{t}$ :

$$
p_{t}=a(L) p_{t-1}+b(L)\left(U_{t}-U^{N}{ }_{t}\right)+c(L) z_{t}+e_{t},
$$

where the unemployment gap is the difference between the actual unemployment rate and the time-varying NAIRU $\left(U_{t}-U^{N}{ }_{t}\right)$. If excess nominal GDP growth is again taken as exogenous, the model can be closed by adding two equations, one of which is (2) above, and the other of which is an "Okun's Law" equation relating the unemployment gap to 
the output gap. ${ }^{4}$

The NAIRU, or alternatively the "natural rate of unemployment," is simply that unemployment rate which is consistent with steady (nonaccelerating or decelerating) inflation. The structure of (3) suggests two alternative concepts of the NAIRU. The standard version is the "no-supply-shock" NAIRU, that is, the unemployment rate which is consistent with steady inflation in the absence of supply shocks. This is the NAIRU that emerges from the estimation of (3) with the $z_{t}$ "supply shock" variables included to control for the influence of supply shocks. For example, if the inflation rate has been steady in the recent past, but then suddenly exhibits a "spike" that is entirely explained by the $z_{t}$ variables, the current unemployment rate is the "no-supply-shock NAIRU" that is compatible with steady inflation in the absence of supply shocks. An alternative unqualified NAIRU would increase sharply in response to an adverse supply shock by the estimated amount of the shock $\left[c(L) z_{\downarrow}\right]$ divided by the sum of the $b$ coefficients.

By taking excess nominal GDP growth as exogenous, the triangle model allows us to focus on the inflation process without the distraction of building a model of the determinants of aggregate demand. Admittedly, this simplification sweeps two-thirds of macroeconomics under the rug. And it ignores channels by which inflation feeds back into the determination of nominal GDP, which may cause econometric bias in inflation equations

4. Using the symbols in the text, an Okun's law equation that closes the model would be:

$$
U_{t}-U^{N}=\theta(L) R_{t}+\epsilon_{t}
$$

Empirically the sum of the $\theta$ coefficients has been around -0.5 for most of the postwar period, although in the 1990-95 subinterval that sum has been close to -1.0. 
The Time-Varying NAIRU, Page 11

in which nominal GDP appears directly an an explanatory variable. As a general proposition, in the presence of contemporaneous feedback from inflation to nominal GDP and of supply shocks that are imperfectly measured, estimates of the triangle-type inflation equation (1) that use nominal GDP as a proxy for the demand $\left(D_{t}\right)$ variable will yield a coefficient on nominal GDP which is biased away from zero. Alternatively, using the output gap or unemployment gap as a proxy for the demand variable will yield a coefficient which is biased toward zero. The more accurately the influence of supply shocks is measured, the smaller the bias. $^{5}$ In their consideration of the endogeneity of the unemployment rate in an inflation equation like (2), King-Watson support the inclusion of unemployment by finding that unemployment Granger-causes inflation, but they do not consider the issue of bias in the coefficient on the unemployment variable in the presence of imperfectly measured supply shocks. ${ }^{6}$

In general, supply shocks create an omitted variable problem in the traditional Phillips curve specification that includes only lagged inflation and the unemployment gap. ${ }^{7}$ One

5. Formal measures of the bias are developed in Gordon (1990b, Table 1, p. 1121).

6. "More specifically, in a reduced form vector autoregression, past unemployment is important for predicting current inflation but past inflation contains little information about current unemployment" (King-Watson, 1994, p. 161).

7. While early work on the Phillips curve focussed on wage behavior, and required a "markup" equation to relate inflation to wage changes, it has proven more useful since the mid-1970s to estimate a reduced-form equation in which inflation is directly related to unemployment, thus eliminating the need to be concerned with the two-way links between wages and prices. A complete set of wage equations for both the U. S. and for Germany, estimated with the same specification as in this paper, can be found in Franz-Gordon (1993). That paper determined that the U. S. wage NAIRU for 1990 was 6.2 percent, almost exactly the same as estimated in this paper for the GDP deflator by the time-varying approach described below. 


\section{The Time-Varying NAIRU, Page 12}

expects inflation to be negatively related to unemployment, but if supply shocks create an extraneous positive correlation between inflation and unemployment and no explicit variables are included to proxy for the influence of supply shocks, then the coefficient on unemployment will be biased toward zero, and the resulting equation is likely to produce unreliable predictions in periods when supply shocks are absent.

\section{Rate of Change Effects}

In previous research I have found that wage and price change depend on both the level and change in the demand variable, i.e., the output gap or unemployment gap. ${ }^{8}$ The role of the change effect is automatically allowed to enter as long as the gap variable is entered with more than one lag. For instance, if the gap variable is entered as the current value and one lagged value and the coefficients are estimated as -0.5 and +0.3 , respectively, then this is identically equal to an equation in which the current level and current change of the gap are entered separately, with respective coefficients of -0.2 and -0.3 . In light of the high statistical significance of the change effect in the results discussed below, time-series equations that do not allow for the change effect (either by entering it directly or by allowing the level of the gap to enter with one or more lags) are misspecified. The change effect is particularly important in explaining macroeconomic price behavior in the 1930 s, a result that I have found previously and that Romer (1996) has recently substantiated.

8. I first noted the importance of the rate-of-change effect in Gordon (1977a, pp. 270-1). 


\section{The Time-Varying NAIRU, Page 13}

\section{Missing Elements: Expectations and Wages}

The original Phillips article was about the relation between wage changes and unemployment. Later, expected inflation was added and we had the "expectational Phillips curve." But the triangle model as summarized above has no expectations and no wages. These are issues of substantive significance.

The omission of expectations is deliberate. Much attention was diverted in the late 1960 s and early 1970 s to the interpretation of the lagged effect of prices on wages as reflecting adaptive lags in the formation of expectations. Since then we have learned that price and wage inertia is compatible with rational expectations. The speed of price adjustment and the speed of expectation formation are two totally different issues. Price adjustment can be delayed by wage and price contracts, and by the time needed for cost increases to percolate through the input-output table, and yet everyone can form expectations promptly and rationally based on full information about the aggregate price

level. The role of the lagged inflation terms in (1) and (3) is to capture the dynamics of inertia, whether related to expectation formation, contracts, delivery lags, or anything else.

As important as the omission of expectations is the omission of wages in the triangle model. The earlier fixation on wages was a mistake. The relationship of prices to wages has changed over time and is not well described by a constant markup equation of the type used in the early Phillips-curve literature. Labor's share in national income exhibits a strong upward movement between the mid-1960s and early 1970s that has not been adequately explained. The Fed's goal is to control inflation, not wage growth, and models with 
separate wage growth and price markup equations do not perform as well as equations like (1) and (2) above in which wages are implicitly solved out and only a reduced form is estimated. By treating the relationship of inflation to unemployment, rather than of wage change to unemployment, the triangle approach returns to the framework of the original Samuelson and Solow article (1960) that coined the term "Phillips curve" and plotted U. S. data on the inflation-unemployment quadrant. The earliest credit for ignoring wages is claimed by Irving Fisher (1926), whose neglected article discovered the Phillips curve in the form of a relationship between the unemployment rate and price changes, not wage changes.

\section{Implications of the Triangle Model}

Whether the unemployment gap or some other demand variable enters an equation like (1) or (3) determining the inflation rate, this equation, together with the assumption that nominal GDP is exogenous as in (2), generates several clear implications.

1. In the long run inflation is "always and everywhere an excess nominal GDP phenomenon." To control inflation, policy needs a nominal anchor, most plausibly the excess growth of nominal GDP itself. Targeting the no-supply-shock NAIRU, or the equivalent level of "natural" or "potential" real GDP, will lead to accelerating inflation in a decade like the 1970 s when supply shocks are significant, serially correlated, and positive (i.e., adverse).

2. There is no special connection between the growth in the money supply and inflation; any effect of money growth on inflation is shared by an identical effect of velocity 
growth on inflation.

3. In the short run, fluctuations in excess nominal GDP growth lead to clockwise loops on a diagram plotting inflation against the unemployment gap. The loops come from inertia, i.e., the role of the lagged dependent variable in equation (3) in slowing the response of the inflation rate to a change in the unemployment gap.

4. Supply shocks can cause a positive correlation between inflation and the unemployment gap. The observation that the Phillips curve correlation between inflation and unemployment was positive rather than negative in the 1970s is consistent with the triangle model, due to its explicit treatment of supply shocks like the rise in oil prices.

5. The triangle model is resolutely Keynesian. Prices are prevented by inertia and by the finite Phillips curve adjustment coefficient (b) from mimicking changes in nominal GDP growth. With excess nominal GDP growth treated as exogenous, the output and unemployment gaps are determined as a residual. However, the triangle model does not incorporate the implication that King-Watson (1994) attribute to their "Keynesian" straw man that "unemployment is dominated by aggregate demand disturbances." Instead, both demand and supply shocks influence both the inflation rate and the unemployment rate. For any given level of excess nominal GDP growth, an adverse supply shock (e.g., an increase in oil prices) raises the inflation rate, reduces the output gap, and raises the unemployment gap.

What theoretical story is consistent with the mainstream triangle model? Agents implicitly are price setters and demand takers. Although the Patinkin-Clower disequilibrium 
framework, as developed by Barro-Grossman (1976) and others, has no model of price setting, it is the right model of quantity determination given whatever sources of inertia and finite Phillips slopes prevent prices from clearing markets. Agents are pushed off notional supply and demand curves by constraints that spill over from rationed markets. Today's macroeconomists tend to brush off the disequilibrium framework because it has no theory of price determination, while forgetting that it has the right theory of output determination.

\section{Validation of the Triangle Model}

The triangle model may be unique in that its textbook version came first, and the econometrics and theory came after that. The textbooks were published in 1978; the basic equations were set out in $1976 .^{9}$ The econometric version, developed in the late 1970 s, was validated in 1981-87 when the sacrifice ratio experienced by the economy (i.e., the percentage loss in output associated with the deceleration of inflation that occurred) corresponded almost exactly to what had been predicted in advance on the basis of parameters estimated through the end of $1980 .^{10}$ Versions of the equation estimated through 1987 in post-sample dynamic simulations tracked quite precisely the acceleration of inflation observed in 1987-90 and the deceleration of inflation that occurred in 1990-93.

9. See Gordon (1977b), a paper presented at the AEA meetings in October, 1976. A diagrammatic version originated in a classroom handout that Rudiger Dornbusch developed at the Chicago Business School in early 1975. Both my version and that of Dornbusch combined a Phillips curve, long-run neutrality, a nominal GDP identity like (2), and a role for exogenous supply shocks.

10. Gordon-King (1982, Table 5, line 3) computed a sacrifice ratio of 6.2 from their econometric version of the triangle model. Using the data available at the time, the cumulative deviation of actual from potential output during the period 1980-87 was 26.2 percent and inflation was reduced by 4.1 percentage points from $1979-80$ to $1985-86$, for an actual sacrifice ratio of 6.4 . 
The positive performance of the triangle model stands in sharp contrast to the shambles in which the Phillips curve literature found itself in the mid-1970s. A central point of departure for Lucas's new classical revolution was the failure of the 1960s Phillips curve. In the language of Lucas and Sargent (1978, pp. 49-50), "that these predictions were wildly incorrect, and that the doctrine on which they were based is fundamentally flawed, are now simple matters of fact ... the task which faces contemporary students of the business cycle [is] that of sorting through the wreackage ... of that remarkable intellectual event called the Keynesian Revolution." The triangle model was in print in its present form before Lucas and Sargent wrote those lines; it has survived and thrived, while empirical attempts by Robert Barro (1978) and others to valididate the new classical policy ineffectiveness proposition failed, running aground on the bedrock of inflation inertia.

\section{Estimating a Time-varying NAIRU}

For almost two decades a time series for the NAIRU has been published in my macroeconomics textbook. My NAIRU series increases from the 1950 s to the 1970 s, following George Perry's (1970) innovation by using a demographic adjustment to the unemployment rate to reflect the rising share of teenagers and females in the labor force during that era. However, when in the late 1980s (Gordon, 1990) I tested to see whether the demographic reversal of the 1980 s (notably a reduced share of teenagers in the labor force) had reduced the NAIRU accordingly, I found that it had not. Without any justification other than its empirical performance, I arbitrarily set the textbook NAIRU equal to 6.0 percent for the entire period after 1978 . The NAIRU series that combines the 
demographic adjustment through 1978 with an assumption that the NAIRU is constant at 6.0 percent thereafter is henceforth called the "textbook NAIRU series." This paper assesses the relative performance of the textbook NAIRU series and an alternative time-varying ("TV") NAIRU series that bases changes in the NAIRU on time-varying parameter estimates.

\section{Form of the Inflation Equation}

The estimation of the TV-NAIRU combines the above inflation equation (3), repeated here, with an explicit specification of the TV-NAIRU:

$$
\begin{aligned}
& p_{t}=a(L) p_{t-1}+b(L)\left(U_{t}-U^{N}{ }_{t}\right)+c(L) z_{t}+e_{t}, \\
& U^{N}{ }_{t}=U^{N}{ }_{t-1}+\epsilon_{t} .
\end{aligned}
$$

In (3) the error term $\epsilon_{t}$ is iid with a mean of zero and a standard deviation of $\sigma_{\epsilon}$. When the standard deviation $\sigma_{\epsilon}=0$, then $U^{N}$ is constant. When $\sigma_{\epsilon} \neq 0$, the model allows the NAIRU to vary by an amount $\epsilon_{t}$ each quarter. If no limit were placed on the ability of $U^{N}$ to vary each time period, then the TV-NAIRU would be free to jump up and down and soak up all the residual variation in the inflation equation. The model (3)-(4) is a standard "stochastic time-varying parameter regression model" that can be estimated using Gaussian maximum likelihood methods as described by Hamilton (1994). It was previously applied to the issue of the NAIRU, using a very different version of (3), by King, Stock, and Watson (1995) and Staiger, Stock, and Watson (1996).

The following are the key elements of the inflation equation (3), as developed in previous papers. The sample period is 1955:2-1996:1, or 164 quarters. All right-hand-side 
variables are allowed to enter with unconstrained distributed lags. Lag lengths are chosen to be identical to those in Gordon (1990). ${ }^{11}$ Note that with a sum of $a(L)$ coefficients equal to unity, inflation remains constant in a steady state with the unemployment rate at the NAIRU $\left(U_{t}-U^{N}{ }_{t}=0\right)$ and with supply shocks absent $\left(z_{t}=0\right)$. Supply shock variables include changes in the relative price of imports, the change in the relative price of food and energy, ${ }^{12}$ and the change in the real effective foreign exchange rate. ${ }^{13}$ Dummy variables are included for the "on" and "off" effects of the Nixon price controls. These dummy variables, and indeed all the other variables, are defined exactly the same as in all my papers starting with (1982b). Also included is the difference between productivity growth and its trend, reflecting the fact that, while most of any cyclical increase or decrease in productivity is reflected in a movement in profits in the same direction, a small fraction remains to

11. The only smoothing structure imposed on the lag distributions involves the lagged dependent variable, where 24 lagged terms enter. Rather than estimating 24 unconstrained coefficients, the lagged dependent variable is entered as a series of four-quarter moving averages of rates of change, e.g., the first variable is a four-quarter average of lags $t-1$ to $t-4$, the next $t-5$ through $t-9$, etc. The coefficients on the individual moving averages are unconstrained. Exclusion tests indicate that the moving averages representing lags 13 through 24 enter with a significance level of between 1 and 2 percent in the two equations displayed in Table 1 for the sample periods 1955-96 and are thus highly significant.

12. The food-energy effect is defined as the difference of the rate of change of the chainweighted consumption deflator minus the rate of change of the chain-weighted consumption deflator net of food and energy. Chain-weighted deflators are available back to 1959 and are linked to the implicit deflator prior to 1959.

13. An additional supply shock variable, the change in sensitive raw materials prices, BCD series 99, was tested and found to be insignificant, with a t-ratio below 1. See Gordon (1994, footnote 7). 
influence the inflation rate in the opposite direction. ${ }^{14}$

\section{Data on Unemployment and Inflation}

Figure 1 displays the actual unemployment rate and the textbook NAIRU. The difference between the actual unemployment rate and the textbook NAIRU is the textbook unemployment gap (separately displayed below in Figure 4). The unemployment gap tells a familiar story of postwar business cycles, with short back-to-back recessions in 1957-58 and 1960-61, and then a long period of excess demand in the 1960 s followed by the mild 1969-70 recession that barely nudged the actual unemployment rate above the NAIRU. More excess demand followed in 1973-74, followed by the severe recessions of 1974-75 and 1981-82. Another cycle occurred in the late 1980s, with excess demand comparable to 1973-74, followed by a positive unemployment gap during 1991-93 and another period of mild excess demand between late 1994 and early 1996.

Figure 2 compares three alternative price indexes from which we will calculate three alternative NAIRU series. The chain-weighted GDP deflator (the basic deflator concept in the U. S. National Income and Product Accounts since early 1996) is convenient to use in the context of the triangle model, since it makes the definition linking output growth, nominal GDP growth, and the inflation rate in equation (2) above hold exactly. A case could be made that it makes more sense for the Fed to stabilize consumer prices than GDP

14. The productivity deviation variable was first introduced in exactly the same form in my (1970) paper. The productivity deviation is defined as the log ratio of actual nonfarm private output per hour to a loglinear piecewise trend running through 1950:Q2, 1954:Q4, 1963:Q3, 1972:Q2, 1978:Q3, 1987:Q3, and 1994:Q3. The 1987-94 growth rate of this trend is 1.07 percent per annum. 
prices, and for this reason we compute alternative NAIRU series for the chain-weighted PCE deflator, also shown in Figure 2. For reference is shown a third series, the inflation rate of CPI-U-X $1 .{ }^{15}$ All three series show the same basic cycles of acceleration and deceleration in the inflation rate, although there are notable differences. In both supply-shock episodes (1974-75 and 1979-81) the consumption deflator and CPI inflation rates accelerate earlier than the GDP deflator, and in 1980-81 they rise further. On average consumer price inflation was more rapid than GDP inflation from 1987 to 1994 , and this is the counterpart of the fact that the real wage grew less rapidly in terms of consumer prices than in terms of product prices. The opposite phenomenon occurred during 1955-60 and 1965-73, when consumer price inflation was slower than inflation in the GDP deflator.

\section{Alternative Time-Varying NAIRU Series}

As indicated above, the model (3)-(4) requires that an assumption be imposed on the smoothness of the computed TV-NAIRU series. An assumption of $\sigma_{\epsilon}=0$ implies a completely constant NAIRU series of 6.0 percent, as shown by the horizontal line in Figure 3. At the other extreme an assumption of $\sigma_{\epsilon}=0.4$ implies a highly variable NAIRU series, as shown by the line with the long dashes in Figure 3. In between are series with assumed standard deviations of 0.1 and 0.2 . Which of these and other possible assumptions about the standard deviation should we make?

This problem is analogous to the choice of a smoothness parameter for the Hodrick-

15. This hybrid series is equal to the CPI before 1967 and after 1982, while between 1967 and 1982 substitutes the current rental-equivalence approach for owner-occuped housing in place of the official CPI pre-1983 treatment that is universally regarded as erroneous. 
Prescott filter so often used to detrend time-series variables. The most sensible standard deviation may not be the same for every variable or topic. If the NAIRU is viewed, to paraphrase Milton Friedman, as "ground out" by the microeconomic structure and behavior of the economy, then it should shift slowly. This is especially true, since the concept of the NAIRU incorporated into equation (3) is the unemployment rate consistent with steady inflation in the absence of supply shocks. Allowing a shift in the NAIRU of 0.1 percentage point per quarter might be considered reasonable and of 0.4 percentage points per quarter as excessively rapid. The zig-zags in the series assuming a standard deviation of 0.4 appear implausible; why should the no-supply-shock NAIRU jump up and down from quarter to quarter? In essence, we propose using a "smoothness prior" to reduce the ambiguity presented by the various NAIRU series in Figure 3. We allow the NAIRU to move around as much as it wants to, subject to the qualification that sharp quarter-to-quarter zig-zags (negative serial correlation) are ruled out.

In the series developed in the rest of the paper, we select a standard deviation $\left(\sigma_{\epsilon}\right)$ of 0.2. As shown in Figure 3, this results in a NAIRU series that exhibits substantial movements but just avoids sharp quarter-to-quarter zig-zags. It declines from 6.0 percent in the mid-1950s to a minimum of 5.3 percent around 1962, rises to a plateau of about 6.2 percent between 1967 and 1972, declines briefly between 1973 and 1978, then exhibits a hump of about 6.5 percent between 1978 and 1982, and then drifts down gradually to 5.7 percent in the final quarter, 1996:1.

Figure 4 compares the unemployment gaps implied by the textbook NAIRU and 
various TV-NAIRU series. We see that all the TV-NAIRU series indicate substantially more excess demand than the textbook series in 1955-57, 1965-70, and 1979-80. For 1995-96 the TV-NAIRU series corresponding to a standard deviation of 0.2 and 0.4 indicate somewhat less excess demand than the textbook series.

Previously (Gordon, 1994) we argued that the behavior of inflation in the 1988-89 expansion and 1990-91 recession period was consistent with the textbook NAIRU assumption of 6.0 percent. Indeed, we shall see that the textbook NAIRU does a very good job of tracking the inflation rate in a dynamic simulation applied to 1987-96. But Figure 4 demonstrates that this evidence presented previously is not sufficient to support the textbook NAIRU prior to 1987 or so. The textbook NAIRU performs well after 1987 simply because during that interval it happens to be quite close to the TV-NAIRU. During most of the period prior to 1987 , the econometrically derived TV-NAIRU is substantially higher than the textbook NAIRU.

\section{Understanding the Amblgulty in Bounding the NAIRU}

Staiger, Stock, and Watson (1996) have cast doubt on the enterprise of estimating the NAIRU, concluding that "a typical $95 \%$ confidence interval for the NAIRU in 1990 is 5.1 percent to 7.7 percent . . . This imprecision suggests caution in using the NAIRU to guide monetary policy." Interestingly, our NAIRU estimate for the GDP deflator, using a standard deviation of 0.2, is 6.2 percent for 1990, close to the midway point of the Staiger et. al. band.

Figure 4 displays five different unemployment gap series, that is, the actual 


\section{The Time-Varying NAIRU, Page 24}

unemployment rate minus five alterative NAIRU series. The alternative gap series look almost the same, are very highly correlated, and result in inflation equations that fit about as well as each other. Accordingly, by standard statistical criteria, one cannot be distinguished from the other, leading to the Staiger et. al. conclusion. However, the smoothness criterion proposed above cuts through this ambiguity by using an economic rather than a statistical criterion to choose between alternative NAIRU series. As we shall see, the remaining ambiguity regarding the NAIRU for the very recent period concerns differences among alternative measures of inflation, which exhibit differing degrees of acceleration, constancy, or deceleration.

\section{Estimated Equations for the GDP Deflator}

The estimated equations are presented in the four columns of Table 1 . Two versions each are estimated for 1955-87 and 1955-96, corresponding to the two alternative NAIRU series (textbook and TV with $\sigma_{\epsilon}=0.2$ ). Estimated sums of coefficients on the lagged dependent (inertia) variable and on the unemployment gap are always highly significant and of the correct sign. No constant is included, an essential element of the approach if the demand variable is defined as a deviation from the NAIRU. The pattern of lag coefficients on the unemployment gap zig-zags, indicating the presence of a rate of change effect. In an alternative version of the equation in column (4), in which the current level and current change in the unemployment gap are entered instead of the current and four lags on the level, the coefficient on the change is -0.99 with a $t$ ratio of -4.0 .

The significance of the various supply variables differs, depending on the sample 
period and on the length of the LDV distribution, but they all have the correct sign. A onepercentage-point excess of productivity growth above trend reduces inflation by about 0.1 percent. A one-percentage-point increase in the relative price of imports raises domestic inflation by 0.06 to 0.09 percent, not far from the average share of imports in GDP during the sample period. Between 30 and 40 percent of the food-energy relative price effect feeds through to inflation in the GDP deflator. And a ten percentage point appreciation in the real exchange rate of the dollar reduces domestic inflation by about 0.1 percent within the first year. The Nixon "on" and "off" dummy variables continue to be essential elements in explaining the dynamics of inflation during the $1971-75$ period. The summary statistics in the middle of Table 1 indicate that the TV-NAIRU equation has residual variance that is about 17 percent lower than the textbook NAIRU equation, in both the 1955-87 and 195596 sample periods.

The next-to-bottom section of Table 1 lists the root-mean-squared errors (RMSE) of versions of the equations in which the sum of coefficients on the LDV have been constrained to sum to unity. These RMSE's are shown for four sub-periods (1955-70, 1971-87:2, 1987:3-1994:3, and 1994:4-1996:1) in order to assess the relative performance of the alternative NAIRU series. As would be expected, the measures of fit are uniformly superior for the TV-NAIRU versions. The largest relative improvement in fit is during the pre-1970 period, indicating that the textbook NAIRU version misses an important source of inflation in 1955-57 and 1965-70, namely that excess demand was substantially greater than implied by the textbook series. An important result is that the equation errors are substantially 
smaller during 1987-94 and in 1994-95 than the average standard error for the entire sample period. This indicates that the basic structure of the inflation equation, as specified more than fifteen years ago, has proven to be very successful in tracking inflation during quite different sets of economic conditions.

The final section at the bottom of Table 1 lists mean errors and RMSE's for dynamic simulations in which the LDV is fed back endogenously over the period 1987:4-1996:1. Separate errors are listed from the same simulations for the final six quarters during which the actual unemployment rate fell below 6.0 percent, 1994:4-1996:1. The results in the lefthand column, based on the textbook NAIRU, uses absolutely no information from the post1987:1 interval to estimate the coefficients. The results in column (2), based on the TVNAIRU, uses post-1987 information to estimate the NAIRU using model (3)-(4) but uses no other post-1987 information.

When actual inflation turns out to be above the simulated rate of inflation, there is a positive mean error, and this occurs for $1987-96$ in all four columns. This implies that during this interval the assumed NAIRU series is too low. A negative mean error means that the assumed NAIRU series is too high. The results for the 34-quarter post-sample simulations are quite encouraging. While the mean error is positive, both the textbook and TV-NAIRU versions are almost exactly on track in the final six quarters. And the root mean squared error of the simulations in all four columns is lower than the standard error of the estimated equation. The textbook NAIRU series predicts almost as well as the TV-NAIRU series and overpredicts inflation by only a modest amount during 1995-96. 
The simulation results in columns (3) and (4) use the coefficients estimated over the full sample period through 1996 and of course yield smaller RMSE's for the 1987-96 simulation. Here it is important to emphasize how little the coefficients change when the sample period is extended and how stable the structure of the inflation process seems to have been during 1987-96 from the perspective of coefficients estimated for the pre-1987 period.

How much do the supply-shock variables change the estimated TV-NAIRU? Figure 5 displays two TV-NAIRU series for the GDP Deflator and a standard deviation of 0.2 , differing only that the solid line displays the TV-NAIRU for the full version of the 1955-96 equation displayed in column (4) of Table 1, while the dashed line shows an alternative TVNAIRU series that omits all right-hand-side variables other than the lagged inflation terms and the set of unemployment gap terms. The results are intuitively plausible - during the 1973-81 period influenced by adverse supply shocks, the TV-NAIRU is much higher when the contribution of the supply shock variables to inflation is ignored. The reverse is due after 1982 , presumably due to the declining real prices of oil and imports.

\section{Nonlinearity}

Recently both Robert Eisner (1996) and George Akerlof, William Dickens, and George Perry (1996) have suggested that the linear specification of the inflation equation (3) is incorrect. Eisner argues that the Phillips curve is concave, that is, flatter when the unemployment rate is below the conventional NAIRU and steeper when the unemployment rate is above the conventional NAIRU. I have tested Eisner's proposition by adding to 
equation (3), in the version displayed in Table 1, column (4), an additional variable equal to zero when the unemployment gap is negative and equal to the unemployment gap when the latter is positive. If Eisner is correct, this "POSGAP" variable would have a significant negative sign, indicating a steeper negative slope for the short-run Phillips curve at unemployment rates above the NAIRU. The sum of coefficients on the POSGAP variable (entered as the current value and four lags) indeed is negative, -0.12 , but the statistical significance of the sum is very weak, with a significance level of 0.61 , far from the conventional 0.05 criterion.

Akerlof et. al. (1996) argue for the opposite nonlinearity, a convex Phillips curve which becomes much flatter when inflation is low and unemployment is above the conventional NAIRU. To test their proposition, I defined another variable equal to zero in all quarters except when the unemployment gap was positive and the four-quarter change in the GDP deflator was below 3.0 percent. The sum of coefficients on this additional variable, entered again as the current value and four lags, is precisely zero. Thus I conclude that the short-run Phillips curve is resolutely linear, at least within the range of inflation and unemployment values observed over the 1955-96 period.

\section{Estimated Equatlons for the PCE Deflator}

Table 2 displays an identical set of results that differs only by using the chainweighted PCE deflator in place of the chain-weighted GDP deflator. Most elements of Table 2 are similar to the corresponding elements of Table 1. Coefficients are similar, except (as would be expected) the coefficients on changes in the relative price of imports 
and of food and energy are higher and more significant in the PCE deflator equations in Table 2 than in the GDP deflator equations in Table 1. The Nixon "off" dummy variables are uniformly small and insignificant in Table 2, in contrast to Table 1 . Goodness of fit statistics are similar in both tables. Perhaps the most notable difference occurs in the bottom two lines of Table 2, where improvement in performance of the TV-NAIRU equation in columns (2) and (4), relative to the textbook NAIRU versions in columns (1) and (3), is much greater for the PCE deflator. The textbook NAIRU causes a substantial overprediction of the inflation rate during 1994-96 that does not occur with the TV NAIRU.

Further insight into the "big miss" of the textbook NAIRU series is presented in Figure 6, which plots the textbook NAIRU against the TV-NAIRU series, using a standard deviation of 0.2 , for both the GDP deflator and the PCE deflator. The TV-NAIRU series for the PCE deflator was fairly close to that for the GDP deflator between 1980 and 1990 but then plummets from 6.2 to 5.2 percent over the $1990-96$ period. In late 1995 and late 1996 there is a sharp disagreement between the textbook NAIRU and the PCE TV-NAIRU regarding demand pressure in the economy; the former implies excess demand and the latter implies excess supply.

Two other consumption-based TV-NAIRU series are displayed in Figure 7. These are for the fixed-weight consumption deflator and CPI-U-X1. The two PCE deflators tell roughly the same story up to the last few years, when PCE TV-NAIRU series for the chainweighted PCE deflator drops well below that for the fixed-weight PCE deflator. It appears that the chain-weighted PCE deflator places a substantially higher weight on consumer 
electronics, especially personal computers, that have exhibited a drastic decline in relative prices in the 1990s. During the mid 1980s the TV-NAIRU for CPI-U-X1 was lower than for the two PCE deflators, but after 1990 it has been somewhat higher.

\section{Splitting the Sample Period}

One possible criticism of the preceding results concerns the length of the sample period. Why should the Fed base its estimate of the current NAIRU on more than forty years of previous data? Why is not the more recent past, say the last 20 years, a more relevant interval for which to estimate the inflation equation? Accordingly, Figure 8 contrasts the full-sample NAIRU estimate for the GDP deflator with a 20 percent standard deviation (the same series as was plotted in Figures 3, 5, and 6) with alternative estimates based on the two halves of the sample period. Splitting the sample period results in a sharp jump in the estimated NAIRU at the break point (1975:1). The two sub-samples result in an estimate of the NAIRU for 1955-74 that is between 0.1 and 0.5 percentage points lower than the full-sample estimate, and an estimate of the NAIRU for 1975-96 that ranges between 0.0 and 0.3 percentage points higher than the full-sample estimate. However, for the purposes of conducting current monetary policy, it is reassuring that the NAIRU estimate for 1996:1 is identical in the full-sample and split-sample alternatives.

The estimated coefficients and performance statistics of the split-sample equations for the GDP deflator are displayed in Table 3. The sum of coefficients on the unemployment gap is somewhat higher in the second sub-sample, while the coefficients on the supply-shock variables are quite different. The mean error and root-mean-squared error in the 1987-96 
dynamic simulation are considerably lower for the split sample results in Table 3 than the full-sample results in Table 1. However, a Chow test just misses accepting the hypothesis of a structural break between the two sub-samples at the conventional 5 percent significance level. ${ }^{16}$

\section{Simulations of Alternative Post-1996 Unemployment Scenarios}

How rapidly would inflation accelerate if the Fed "let her rip" (referring to the economy, not interest rates) and allowed unemployment to fall one percentage point below the NAIRU? We can simulate our inflation model, assuming all future values of the supply shock variables are zero, and specify an artificial unemployment gap scenario that generates an acceleration of inflation. The particular scenario plotted by the dashed line in Figure 9 allows the unemployment gap (actual unemployment minus NAIRU) to decline from 0.0 in 1996:2 to -1.0 in 1997:2 and thereafter. The prediction of inflation is based on the 195596 inflation equation coefficients estimated in column (4) of Table 1, that is, using the TVNAIRU. The predictions are compared with a baseline prediction that leaves the unemployment gap at zero forever, starting in 1996:2.

The simulations of the negative unemployment gap scenario display a rapid acceleration of inflation during 1997, reflecting the fact that the pattern of lag coefficients on the unemployment gap variable embodies a "rate-of-change" effect as well as a "level" effect. After the economy settles down at an unemployment gap of -1.0 percent, the rate-of-

16. The $F(28,108)$ ratio is 1.51 , compared to a 5 percent significance value of 1.57 and a 1 percent significance value of 1.89 . 
change effect temporarily interrupts the acceleration of inflation in early 1998, after which the acceleration proceeds steadily, reaching 5.4 percent by the year 2005 . Many journalists and financial market experts would be surprised at the slow pace of this acceleration, although it is clear that the bond market would be "spooked" by the rapid pace of inflation acceleration during 1997. A constant unemployment gap set at zero causes the economy to settled down to an inflation rate of 2.3 percent forever.

\section{Conclusion}

\section{The Triangle Model and the Time-Varying NAIRU}

The inflation process in the United States is one of the most important macroeconomic phenomena in the world, but it is also one of the best understood. In contrast to the wild gyrations of inflation in many other countries, the U. S. inflation process is dominated by inertia. Inflation changes little from year to year, and any deviation of the actual unemployment rate from the NAIRU has extremely small consequences in the short run. The best example is the $1988-90$ period, when unemployment was on average about one percentage point below the 6.2 percent estimated NAIRU, and the GDP deflator accelerated over the three years $1987-90$ from 3.1 to 4.4 percent. This implies a response of inflation of a bit less than half a point per one percentage point that unemployment remains below the NAIRU for a single year. The estimated coefficient on the unemployment gap in Table 1, line 2, ranges from -0.60 to -0.69 , somewhat above one-half.

Because the U. S. inflation process has been so stable, and is so well characterized by 
the triangle model of inflation developed in the late 1970 s and early 1980 s, that model has performed extremely well in dynamic post-sample simulations extending out for up to a decade after the end of the sample period. In such simulations the model has proven capable of tracking the disinflation of the early and mid 1980s, the acceleration of inflation of the late 1980s, and the subsequent deceleration of inflation in the 1990s. Those empirical successes were achieved despite the fact in previous research, the NAIRU inserted into the model was assumed arbitrarily to be constant at 6.0 percent for the entire period after 1978 rather than estimated econometrically.

The main contribution of this paper has been to allow the NAIRU to vary each quarter over the period between 1955 and 1996. The resulting time-varying (TV) NAIRU stays remarkably close to 6 percent over the entire four-decade interval, ranging between extreme values of 5.3 and 6.5 percent. In recent years there has been a downward drift in the NAIRU from around 6.2 percent in the late $1980 \mathrm{~s}$ to current estimates of 5.7 percent for the GDP deflator and 5.2 percent for the PCE deflator. The fact that the TV-NAIRU was very close to 6 percent during the expansion of the late 1980s and recession of 1990-91 helps to explain how my previous assumption that the NAIRU was fixed at 6.0 percent performed so well in tracking the acceleration and deceleration of that period.

This paper rejects the recent argument that the band of statistical uncertainty surrounding the NAIRU is so broad as to render the concept useless for the conduct of policy. We propose an economic criterion based on smoothness, rather than a statistical criterion, to choose among alternative NAIRU estimates for any given measure of inflation. 


\section{The Tlme-Varying NAIRU, Page 34}

The recent suggestion of Staiger $e t$. al. (1996) that the NAIRU for the year 1990 could range from 5.1 to 7.7 percent makes no economic sense. If the NAIRU had been 5.1 percent in the period since 1987, inflation would not have accelerated during 1987-90, since the actual unemployment rate never fell below 5.1 percent in any calendar quarter. If the NAIRU had been 7.7 percent in the period since 1987, inflation would not have decelerated during 1990-93, since the actual unemployment rate never rose above 7.7 percent in any calendar quarter. The fact that the inflation rate for the GDP deflator was roughly constant during the six quarters (1994:4-1996:1), when the actual unemployment rate was approximately constant at 5.6 percent, suggests that the TV-NAIRU for the GDP deflator during those six quarters was very close to 5.6 percent.

The new TV-NAIRU series allows a new series for potential output to be created, measuring the real GDP that can be produced each quarter when the economy is operating at the TV-NAIRU. I have produced such a series by estimating an Okun's law equation like that written above in footnote 4; the resulting series on potential output increases at an annual rate of 2.07 percent between 1990:3 and 1996:1. ${ }^{17}$ Since the TV-NAIRU declines from 6.2 percent in 1990 to 5.7 percent in 1996, this potential output series grows at about 0.1 percentage point faster than would be implied by a NAIRU fixed at 6.0 percent. Thus

17. In estimating the Okun's law equation written in equation (4), I invert it to regress the unknown output gap on current and leading values of the unemployment gap implied by the new TV-NAIRU series based on the GDP deflator and a standard deviation of 0.2 . I allow the sum of coefficients on the unemployment gap to differ during 1990-96 from their values in 1972-90. I calculate the fitted output gap, and then compute a trial value of potential output as actual real GDP minus the fitted output gap. The final potential output series is a 12-quarter centered moving average of the trial series. 
caution is advised regarding the advice of "growth hawks" that the U. S. economy could grow at 3 percent or more per annum if only the Fed's monetary policy is less restrictive. Since the economy is currently at the NAIRU, the ceiling on non-inflationary growth is about 2.1 percent a year, unless the NAIRU falls further below its values of early 1996.

\section{The Conduct of Monetary Policy}

What evaluation of past and current monetary policy is implied by this new research on the NAIRU? According to our new TV-NAIRU measures, there was considerably more excess demand in 1955-57 and 1965-70 than implied by the previous textbook NAIRU series, suggesting that monetary policy was even more overly expansionary in those periods than was previously thought. The new TV-NAIRU series also boosts modestly the extent of estimated excess demand in $1979-80$ and 1988-90. However, the new series implies that monetary policy in $1995-96$ has been almost precisely on target, with an average unemployment rate during the six quarters $1994: 4-1996: 1$ of 5.6 percent, only slightly below the average estimated TV-NAIRU of 5.7 percent for the GDP deflator in that interval. If the Fed considers its goal as the stabilization of the rate of change of the PCE deflator rather than the GDP deflator, then the estimated average TV-NAIRU during the same interval was 5.3 percent, implying that monetary policy was slightly too restrictive in 1995 96.

The TV-NAIRU by any measure has declined in the 1990 s. If the Fed's current deliberations about interest rate changes are intended to influence the actual unemployment rate roughly one year from now, should the Fed extrapolate the recent decline in the 
NAIRU into the future, or should the Fed set its estimate of the NAIRU one year hence equal to the current value? The TV-NAIRU specified in equation (4) above is a random walk and thus is just as likely to increase over the subsequent year as to continue to decrease. There is no information about future inflation available beyond that contained in the lagged values of the explanatory variables in the inflation equation that are already used to derive the NAIRU.

While the TV-NAIRU technique does not provide a magic crystal ball that allows the Fed to see into the future, it makes two valuable contributions to the conduct of monetary policy. First, it quantifies in a systematic way the Fed's intuitive feeling that the NAIRU must have fallen in the 1990s, because as of early 1996 inflation had not accelerated as it did in 1988-90. Second, it highlights the differences in the TV-NAIRU series implied by alternative inflation measures, e.g., the GDP vs. PCE deflator, and forces the Fed to take a stand on what inflation concept it is trying to stabilize.

Estimated movements in the NAIRU over time naturally raise the question as to which factors caused these movements. This question is most easily posed for the three consumption price indexes used to generate the TV-NAIRU series of Figure 7. There only two major changes occur, an increase in the NAIRU from about 5.8 percent in 1965 to roughly 6.5 percent in the two decades after 1970 , and then a decline from about 6.4 percent in 1990 to 5.3 percent in 1996 . The late 1960 s were a time of labor militancy, relatively strong unions, a relatively high minimum wage, and a marked increase in labor's share in national income. The 1990 s have been a time of labor peace, relatively weak 
unions, a relatively low minimum wage, and a very slight decline in labor's income share. The role played in the recent decline of the NAIRU by these aspects of labor market structure, and other plausible causes relating to global competition, remains a tantalizing topic for future research. 


\section{REFERENCES}

Akerlof, George A., Dickens, William T., and Perry, George L. "The Macroeconomics of Low Inflation." Brookings Papers on Economic Activity, 1996, 27:1, forthcoming.

Barro, Robert J. "Unanticipated Money, Output, and the Price Level in the United States." Journal of Political Economy (August 1978), 67, 101-15.

Barro, Robert J., and Grossman, Herschel I. Money, Employment, and Inflation. Cambridge UK: Cambridge University Press, 1976.

Eisner, Robert. "A New View of the NAIRU." Manuscript, Northwestern University, June, 1996.

Fisher, Irving. "A Statistical Relation between Unemployment and Price Changes." International Labor Review, June 1926, 13, 785-92. Reprinted in Journal of Political Economy, March/April 1973, 81, 496-502.

Franz, Wolfgang, and Gordon, Robert J. "Wage and Price Dynamics in Germany and America: Differences and Common Themes". European Economic Review, May 1993, 37, 719-54.

Friedman, Milton. "The Role of Monetary Policy." American Economic Review, March $1968,58,1-17$.

Gordon, Robert J. "The Recent Acceleration of Inflation and its Lessons for the Future." Brookings Papers on Economic Activity, 1970, 1:1, 8-41.

Gordon, Robert J. "The Impact of Aggregate Demand on Prices." Brookings Papers on Economic Activity, 1975, 6:3, 613-62.

Gordon, Robert J. "Can the Inflation of the 1970s Be Explained?" Brookings Papers on Economic Activity, 1977(a), 8:1, 253-77.

Gordon, Robert J. "The Theory of Domestic Inflation." American Economic Review Papers and Proceedings, February 1977(b), 67, 128-34.

Gordon, Robert J. "Price Inertia and Policy Ineffectiveness in the United States, 1890-1980." Joumal of Political Economy, December 1982(a), 90, 1087-1117.

Gordon, Robert J. "Inflation, Flexible Exchange Rates, and the Natural Rate of 
Unemployment." In Baily, M. N., ed., Workers, Jobs, and Inflation. Washington: Brookings Institution, 1982(b), 88-152.

Gordon, Robert J. "U.S. Inflation, Labor's Share, and the Natural Rate of Unemployment." In König, Heinz, ed., Economics of Wage Determination. Berlin and New York: Springer Verlag, 1990(a), pp. 1-34.

Gordon, Robert J. "What Is New-Keynesian Economics?" Journal of Economic Literature, September, 1990(b), 28, 1115-71.

Gordon, Robert J. "Inflation and Unemployment: Where is the NAIRU?" Paper presented to Board of Governors, Federal Reserve System, Meeting of Academic Consultants, December 1, 1994.

Gordon, Robert J. and King, Stephen R. "The Output Cost of Disinflation in Traditional and Vector Autoregressive Models." Brookings Papers on Economic Activity, 1982, $13: 1,205-42$.

Hamilton, James D. Time Series Analysis. Princeton: Princeton University Press, 1994.

King, Robert G. and Watson, Mark W. "The post-war U. S. Phillips curve: a revisionist econometric history." Carnegie-Rochester Conference Series on Public Policy, 1994, 41, 157-219.

King, Robert G., Stock, James H., and Watson, Mark W. "Temporal Instability of the Unemployment-Inflation Relationship. Economic Perspectives of the Federal Reserve Bank of Chicago, May/June 1995, 2-12.

Lucas, Robert E., Jr., and Sargent, Thomas J. "After Keynesian Econometrics." In After the Phillips Curve: Persistence of High Inflation and High Unemployment, Conference Series 19 (Boston: Federal Reserve Bank of Boston, 1978), 49-72.

Perry, George L. "Changing Labor Markets and Inflation." Brookings Papers on Economic Activity, 1970, 1:3, 411-41.

Phillips, A. W. "The Relation between Unemployment and the Rate of Change of Money Wage Rates in the United Kingdom, 1861-1957." Economica, November 1958, 25, 283-99.

Romer, Christina D. "Inflation and the Growth Rate of Output." NBER Working Paper 5575, May 1996. 
Samuelson, Paul A. and Solow, Robert M. "Analytical Aspects of Anti-Inflation Policy." American Economic Review Papers and Proceedings, May 1960, 50, 177-94.

Schultze, Charles L. "Falling Profits, Rising Profit Margins, and the Full Employment Profit Rate," Brookings Papers on Economic Activity, 1975, 6:2, 449-69.

Solow, Robert M. Price Expectations and the Phillips Curve. Manchester, UK: Manchester University Press, 1969.

Staiger, Douglas, Stock, James H., and Watson, Mark W. "How Precise are Estimates of the Natural Rate of Unemployment?" NBER Working Paper 5477, March 1996.

Stevenson, Richard W. "It's Heresy at Fed But Critics Say: Step on the Gas." New York Times, June 7, 1996, C1, C15 (Chicago edition). 


\section{TABLE 1}

Estimated Equations for Quarterly Change in Chain-Weight GDP Deflator, Alternative Sample Periods and Unemployment Gaps

\begin{tabular}{|c|c|c|c|c|c|}
\hline \multirow[b]{2}{*}{ Variable } & \multirow[b]{2}{*}{ Lags } & \multicolumn{2}{|c|}{ 1955:2-1987:3 } & \multicolumn{2}{|c|}{ 1955:2-1996:1 } \\
\hline & & $\begin{array}{l}\text { Textbook } \\
\text { (1) }\end{array}$ & $\begin{array}{c}\text { TV (0.2) } \\
(2)\end{array}$ & $\begin{array}{c}\text { Textbook } \\
\text { (3) }\end{array}$ & $\begin{array}{c}\text { TV (0.2) } \\
\text { (4) }\end{array}$ \\
\hline 1. $\triangle$ Chain-Weight GDP deflator & $1-24$ & $1.06^{* *}$ & $1.01^{* \bullet}$ & $1.05^{* *}$ & $1.01^{* *}$ \\
\hline 2. Unemployment Gap & $0-4$ & $-0.69 * *$ & $-0.62 * *$ & $-0.64^{* *}$ & $-0.60 * *$ \\
\hline 3. $\Delta$ Productivity deviation & $0-1$ & -0.10 & $-0.11^{*}$ & -0.08 & $-0.09 *$ \\
\hline 4. $\Delta$ Relative Import Price & $1-4$ & 0.06 & $0.08^{*}$ & 0.07 & $0.09^{* *}$ \\
\hline 5. $\Delta$ Relative Price Food-Energy & $0-4$ & 0.43 & $0.42^{*}$ & 0.28 & $0.30^{*}$ \\
\hline 7. $\Delta$ Effective Real Exchange Rate & $0-3$ & -0.01 & -0.01 & -0.01 & -0.01 \\
\hline 8. Nixon "on" & 0 & $-1.56^{\circ}$ & $-1.62^{* *}$ & $-1.59^{* *}$ & $-1.69^{* *}$ \\
\hline 9. Nixon "off" & 0 & $2.31 * 0$ & $2.19^{\cdots \bullet}$ & $2.09 * *$ & $2.07 * *$ \\
\hline$\overline{\mathrm{R}}^{2}$ & & 0.85 & 0.88 & 0.85 & 0.87 \\
\hline S.E.E. & & 1.01 & 0.92 & 0.95 & 0.87 \\
\hline S.S.R. & & 104.8 & 86.7 & 123.1 & 103.4 \\
\hline $\begin{array}{l}\text { Restricted Version, RMSE in sub- } \\
\text { intervals of fitted sample } \\
\text { 1955:2-70:4 } \\
\text { 1971:1-87:2 } \\
1987: 3-94: 3 \\
1994: 4-96: 1\end{array}$ & & $\begin{array}{l}1.05 \\
0.77 \\
- \\
-\end{array}$ & $\begin{array}{l}0.92 \\
0.71 \\
\cdot \\
-\end{array}$ & $\begin{array}{l}1.07 \\
0.80 \\
0.63 \\
0.47\end{array}$ & $\begin{array}{l}0.93 \\
0.73 \\
0.61 \\
0.42\end{array}$ \\
\hline $\begin{array}{l}\text { Dynamic Simulation } \\
1987.041996 .01\end{array}$ & & & & & \\
\hline $\begin{array}{l}\text { Mean Error } \\
\text { Root Mean-Squared Error } \\
\text { 1994:Q41996:Q1 }\end{array}$ & & $\begin{array}{l}0.24 \\
0.91\end{array}$ & $\begin{array}{l}0.20 \\
0.86\end{array}$ & $\begin{array}{l}0.34 \\
0.70\end{array}$ & $\begin{array}{l}0.26 \\
0.65\end{array}$ \\
\hline $\begin{array}{l}\text { Mean Error } \\
\text { Root Mean-Squared Error }\end{array}$ & & $\begin{array}{r}-0.10 \\
0.48\end{array}$ & $\begin{array}{l}0.08 \\
0.41\end{array}$ & $\begin{array}{r}-0.01 \\
0.39\end{array}$ & $\begin{array}{l}0.12 \\
0.40\end{array}$ \\
\hline
\end{tabular}

Notes: $\quad(*)$ indicates that coefficient or sum of coefficients is significant at 5 percent level; $\left({ }^{* *}\right)$ at 1 percent level 
TABLE 2

Estimated Equations for Quarterly Change in Chain-Weight PCE Deflator, Alternative Sample Periods and Unemployment Gaps

\begin{tabular}{|c|c|c|c|c|c|}
\hline \multirow[b]{2}{*}{ Varlable } & \multirow[b]{2}{*}{ Laga } & \multicolumn{2}{|c|}{ 1955:2-1987:3 } & \multicolumn{2}{|c|}{ 1955:2-1996:1 } \\
\hline & & $\begin{array}{l}\text { Textbook } \\
\text { (1) }\end{array}$ & $\begin{array}{l}\text { TV (0.2) } \\
\text { (2) }\end{array}$ & $\begin{array}{l}\text { Textbook } \\
\text { (3) }\end{array}$ & $\begin{array}{c}\text { TV (02) } \\
\text { (4) }\end{array}$ \\
\hline 1. $\triangle$ Fixed-weight GDP deflator & 1.24 & $1.09 * *$ & $1.01^{* *}$ & $1.07^{* *}$ & $1.01^{* *}$ \\
\hline 2. Unemployment Gap & $0-4$ & $-0.77^{* *}$ & $-0.66^{* *}$ & $-0.68 * *$ & $-0.67^{* *}$ \\
\hline 3. $\Delta$ Productivity deviation & $0-1$ & -0.02 & -0.03 & -0.02 & -0.03 \\
\hline 4. $\Delta$ Relative Import Price & $1-4$ & $0.11^{* *}$ & $0.14^{* *}$ & $0.11^{* *}$ & $0.14^{* *}$ \\
\hline 5. $\Delta$ Relative Price Food-Energy & $0-4$ & $0.74^{* *}$ & $0.66^{* *}$ & $0.66^{* *}$ & $0.64^{* *}$ \\
\hline 7. $\Delta$ Effective Real Exchange Rate & $0-3$ & -0.01 & -0.00 & -0.00 & -0.00 \\
\hline 8. Nixon "on" & $\mathbf{0}$ & $-1.82^{* *}$ & $-1.95^{* *}$ & $-1.74^{* *}$ & $-2.03^{* *}$ \\
\hline 9. Nixon "offe & 0 & 0.01 & -0.47 & 0.05 & -0.39 \\
\hline$\overline{\mathrm{R}}^{2}$ & & 0.87 & 0.88 & 0.86 & 0.88 \\
\hline S.E.E. & & 1.03 & 0.99 & 0.98 & 0.90 \\
\hline S.S.R. & & 108.8 & 99.6 & 129.8 & 111.4 \\
\hline $\begin{array}{l}\text { Restricted Version, RMSE in sub- } \\
\text { intervals of fitted sample } \\
\text { 1955:2-70:4 } \\
\text { 1971:1-87:2 } \\
\text { 1987:3-94:3 } \\
\text { 1994:4-96:1 }\end{array}$ & & $\begin{array}{l}1.11 \\
0.80 \\
- \\
-\end{array}$ & $\begin{array}{l}0.99 \\
0.75 \\
- \\
-\end{array}$ & $\begin{array}{l}1.11 \\
0.82 \\
0.68 \\
0.75\end{array}$ & $\begin{array}{l}0.99 \\
0.77 \\
0.57 \\
0.52\end{array}$ \\
\hline $\begin{array}{l}\text { Dynamic Simulntion } \\
\text { 1987:Q4-1996:Q1 }\end{array}$ & & & & & \\
\hline $\begin{array}{l}\text { Mean Error } \\
\text { Root Mean-Squared Error } \\
\text { 1994:Q41996:Q1 }\end{array}$ & & $\begin{array}{l}0.19 \\
0.83\end{array}$ & $\begin{array}{l}0.35 \\
0.72\end{array}$ & $\begin{array}{l}0.24 \\
0.75\end{array}$ & $\begin{array}{l}0.35 \\
0.65\end{array}$ \\
\hline $\begin{array}{l}\text { Mean Error } \\
\text { Root Mean-Squared Error }\end{array}$ & & $\begin{array}{r}-0.72 \\
0.78\end{array}$ & $\begin{array}{r}-0.07 \\
0.26\end{array}$ & $\begin{array}{r}-0.61 \\
0.68\end{array}$ & $\begin{array}{r}-0.03 \\
0.25\end{array}$ \\
\hline
\end{tabular}

Notes: ( $\quad$ ( ) indicates that coefficient or sum of coefficients is significant at 5 percent level; (**) at 1 percent level. 
TABLE 3

Estimated Equations for Quarterly Change in Chain-Weight GDP Deflator, Alternative Sub-Sample Periods and Unemployment Gaps

\begin{tabular}{|c|c|c|c|c|c|}
\hline \multirow[b]{2}{*}{ Variable } & \multirow[b]{2}{*}{ Lags } & \multicolumn{2}{|c|}{ 1955:2-1974:4 } & \multicolumn{2}{|c|}{ 1975:1-1996:1 } \\
\hline & & $\begin{array}{c}\text { Textbook } \\
\text { (1) }\end{array}$ & $\begin{array}{c}\text { TV (02) } \\
\text { (2) }\end{array}$ & $\begin{array}{c}\text { Textbook } \\
\text { (3) }\end{array}$ & $\begin{array}{c}\text { TV (0.2) } \\
(4)\end{array}$ \\
\hline 1. $\triangle$ Chain-weight GDP deflator & $1-24$ & $1.02^{* *}$ & $0.94^{* *}$ & $1.07^{* *}$ & $1.06^{* *}$ \\
\hline 2. Unemployment Gap & $0-4$ & $-0.63^{* *}$ & $-0.68 * *$ & $-0.74^{* *}$ & $-0.86^{* *}$ \\
\hline 3. $\Delta$ Productivity deviation & $0-1$ & -0.11 & $-0.13^{* *}$ & -0.04 & -0.04 \\
\hline 4. $\Delta$ Relative Import Price & $1-4$ & -0.02 & 0.02 & $0.11^{* *}$ & $0.13^{* *}$ \\
\hline 5. $\Delta$ Relative Price Food-Energy & $0-4$ & 0.29 & 0.31 & $0.21 * *$ & 0.03 \\
\hline 7. $\Delta$ Effective Real Exchange Rate & $0-3$ & -0.05 & -0.06 & 0.00 & 0.01 \\
\hline 8. Nixon "on" & 0 & -1.80 & -1.27 & - & - \\
\hline 9. Nixon "off" & 0 & $4.74^{\circ}$ & $4.20^{\circ}$ & - & - \\
\hline$\overline{\mathbf{R}}$ & & 0.78 & 0.83 & 0.92 & 0.93 \\
\hline S.E.E. & & 1.12 & 1.00 & 0.67 & 0.63 \\
\hline S.S.R. & & 64.3 & 50.8 & 26.7 & 23.4 \\
\hline $\begin{array}{l}\text { Restricted Version, RMSE in sub- } \\
\text { intervals of fitted sample } \\
\text { 1955:2-70:4 } \\
1971: 1-87: 2 \\
1987: 3-94: 3 \\
1994: 496: 1\end{array}$ & & $\begin{array}{l}0.93 \\
- \\
- \\
-\end{array}$ & $\begin{array}{l}0.80 \\
- \\
- \\
-\end{array}$ & $\begin{array}{l}- \\
\overline{0} \\
0.55 \\
0.42\end{array}$ & $\begin{array}{l}- \\
- \\
0.40 \\
0.24\end{array}$ \\
\hline $\begin{array}{l}\text { Dynamic Simulation } \\
\text { 1987:Q4-1996:Q1 } \\
\text { Mean Error } \\
\text { Root Mean-Squared Error } \\
\text { 1994:Q4-199:Q1 } \\
\text { Mean Error } \\
\text { Root Mean-Squared Error }\end{array}$ & & - & $\begin{array}{l}- \\
- \\
-\end{array}$ & $\begin{array}{r}0.33 \\
0.63 \\
\\
-0.00 \\
0.31\end{array}$ & $\begin{array}{l}0.08 \\
0.39 \\
0.01 \\
0.23\end{array}$ \\
\hline
\end{tabular}

Notes: $\quad\left({ }^{*}\right)$ indicates that coefficient or sum of coefficients is significant at 5 percent level; $\left({ }^{* *}\right)$ at 1 percent level. 


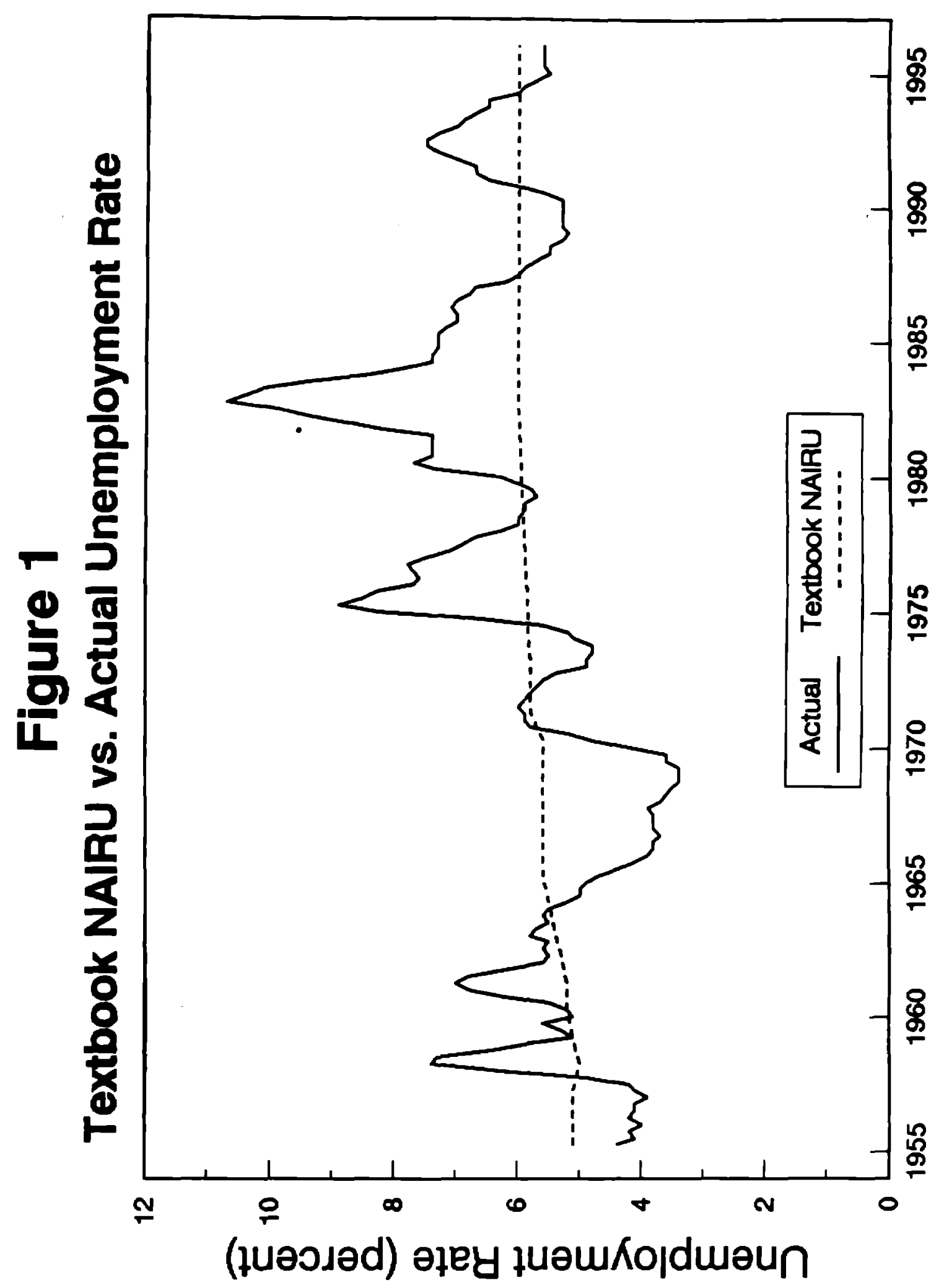




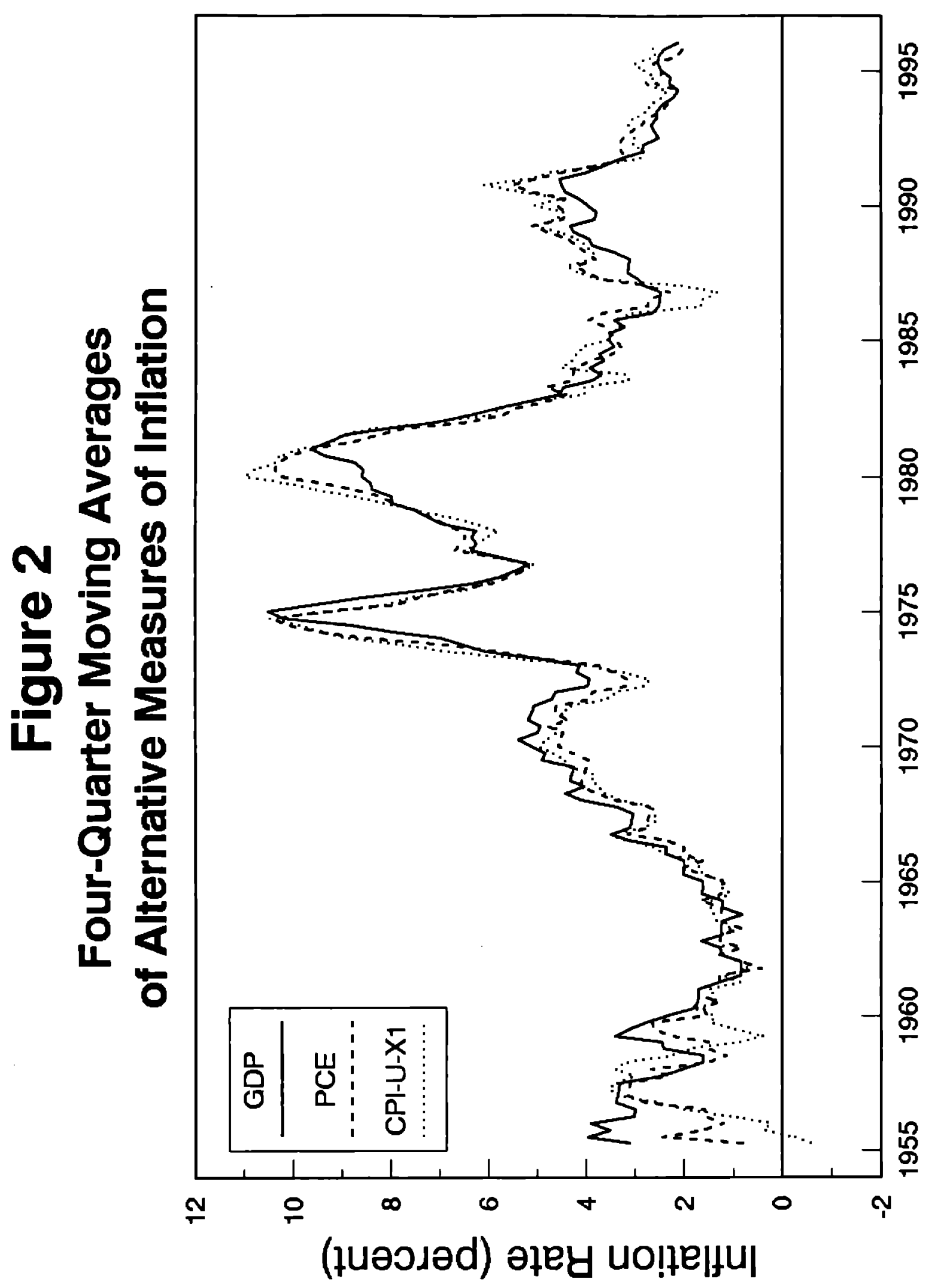




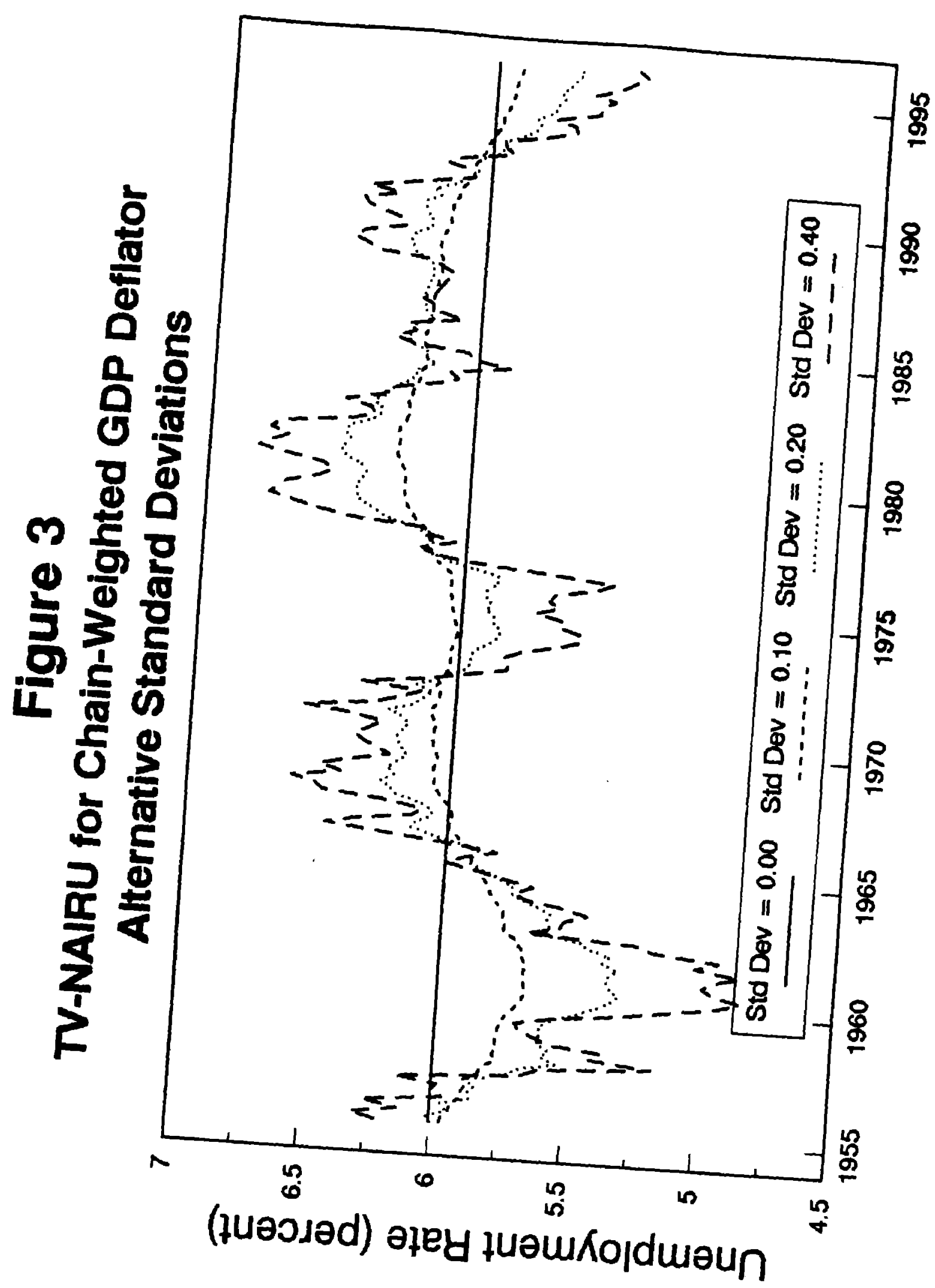




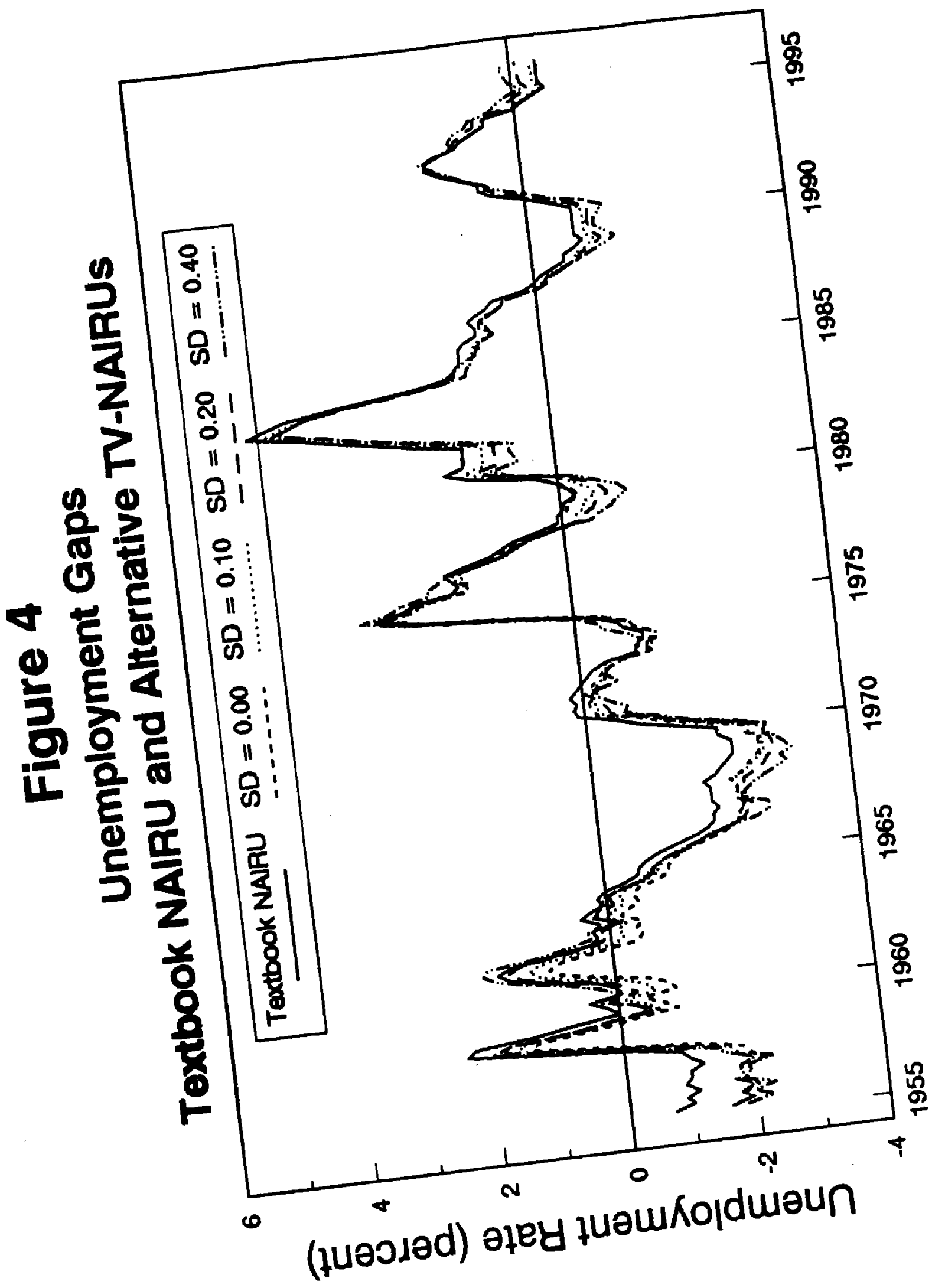




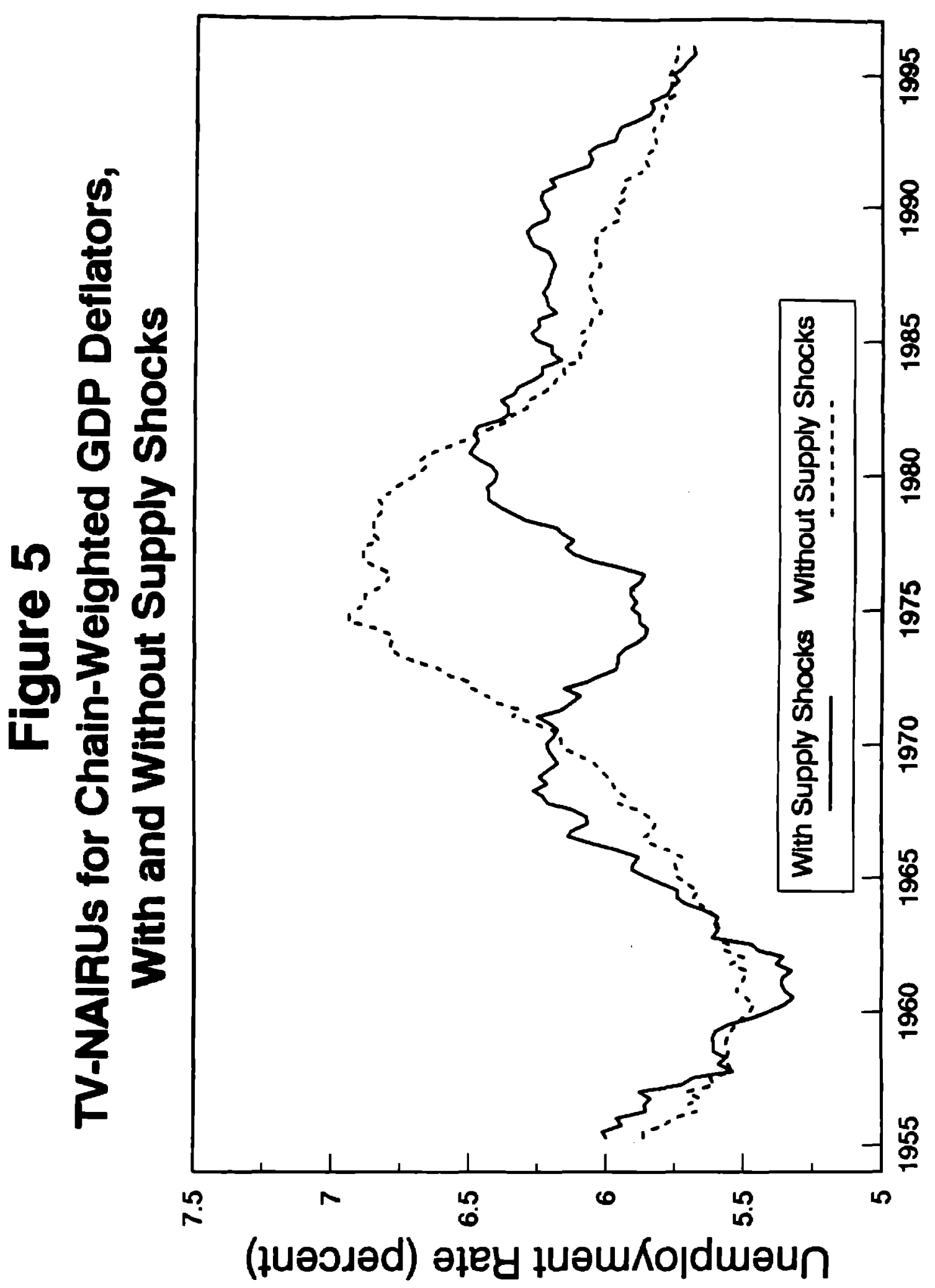




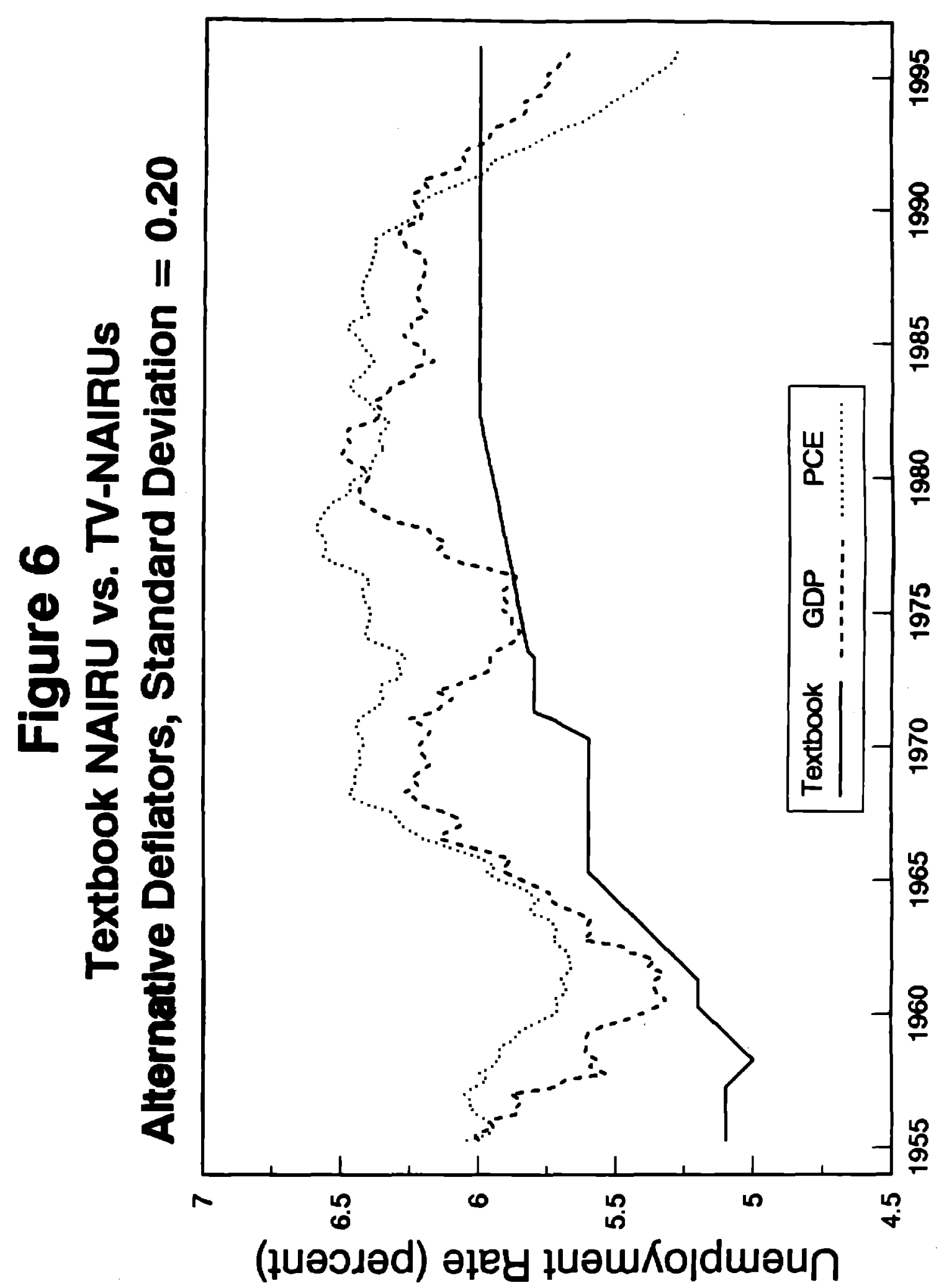




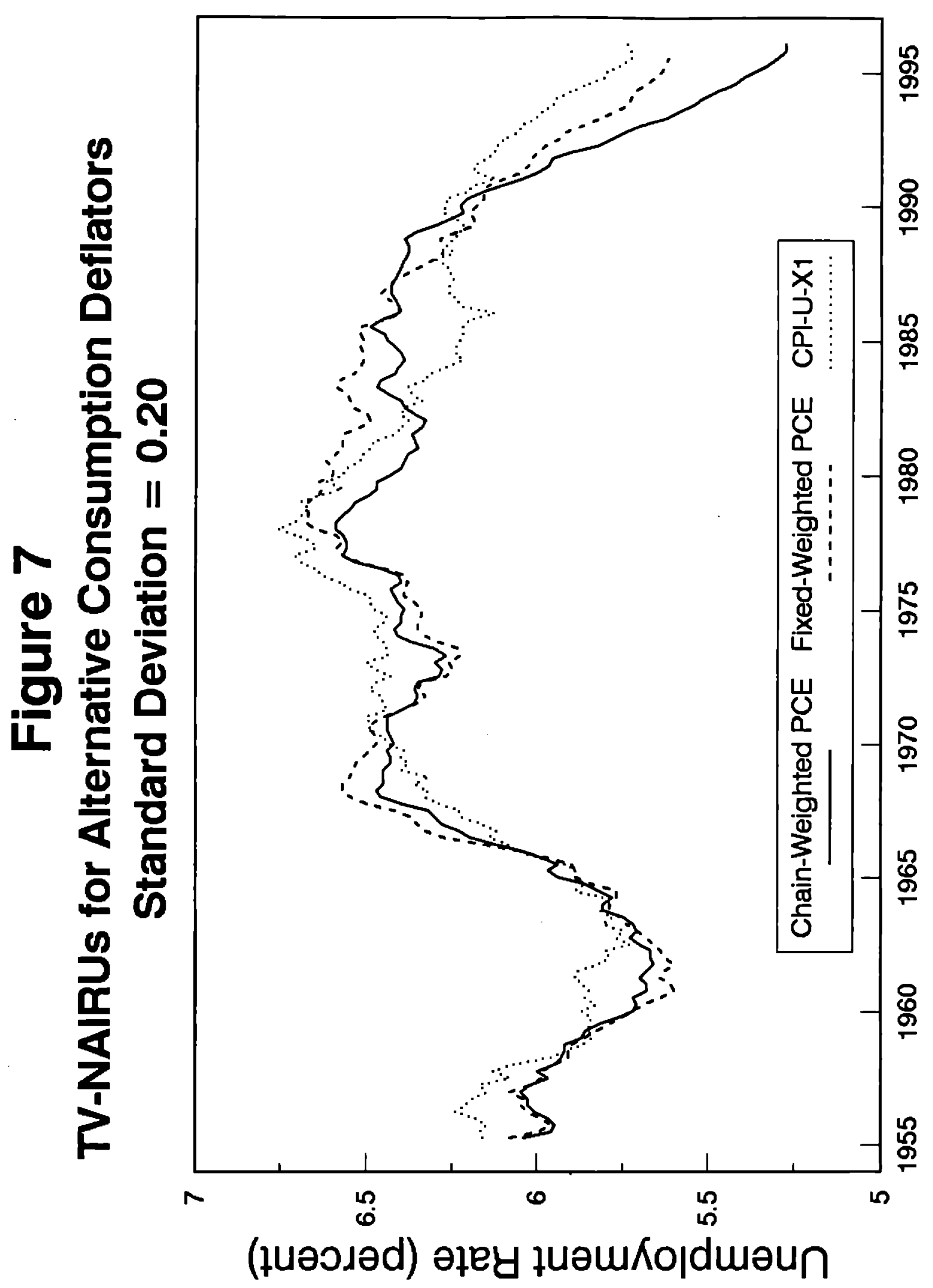




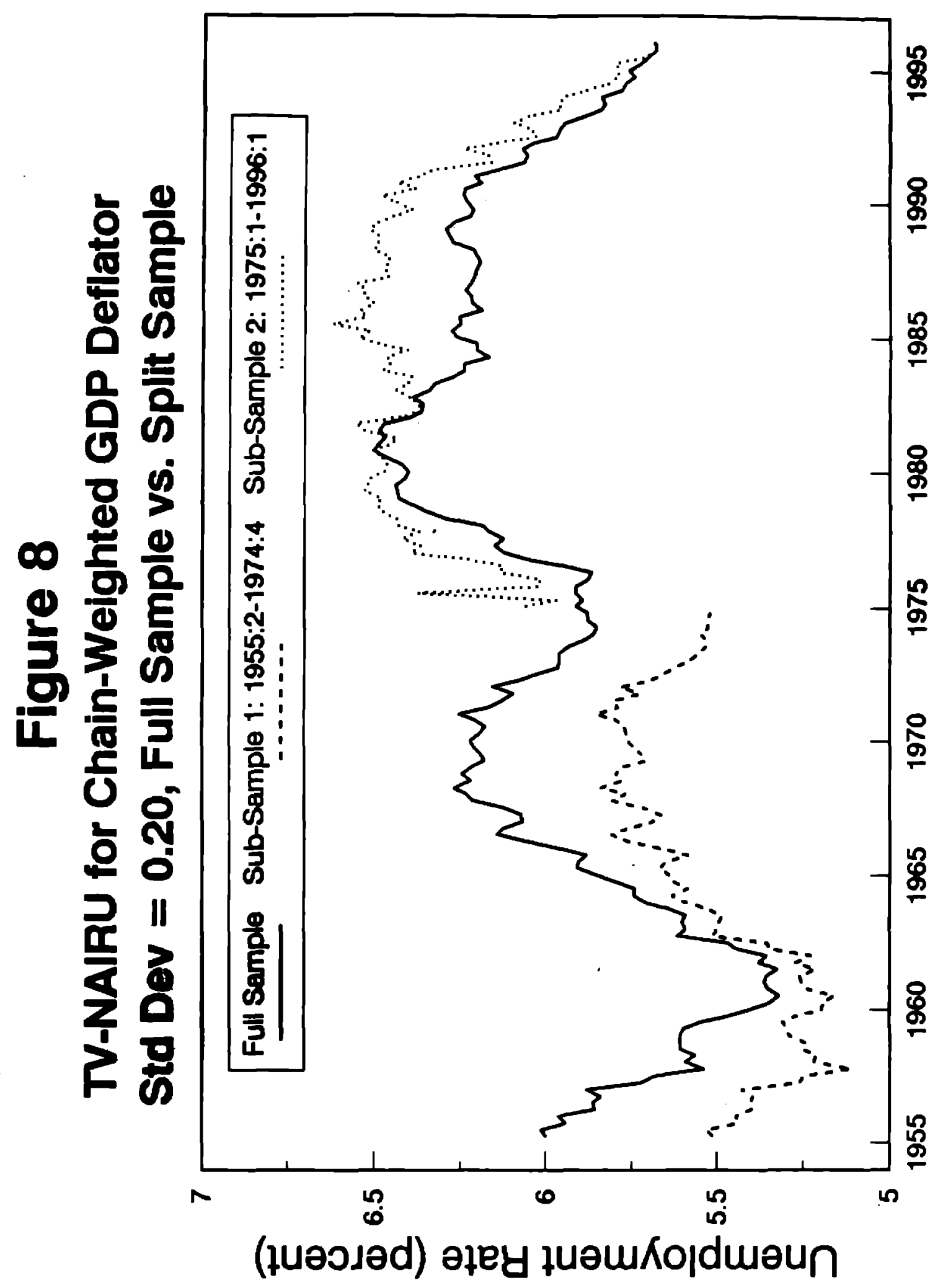




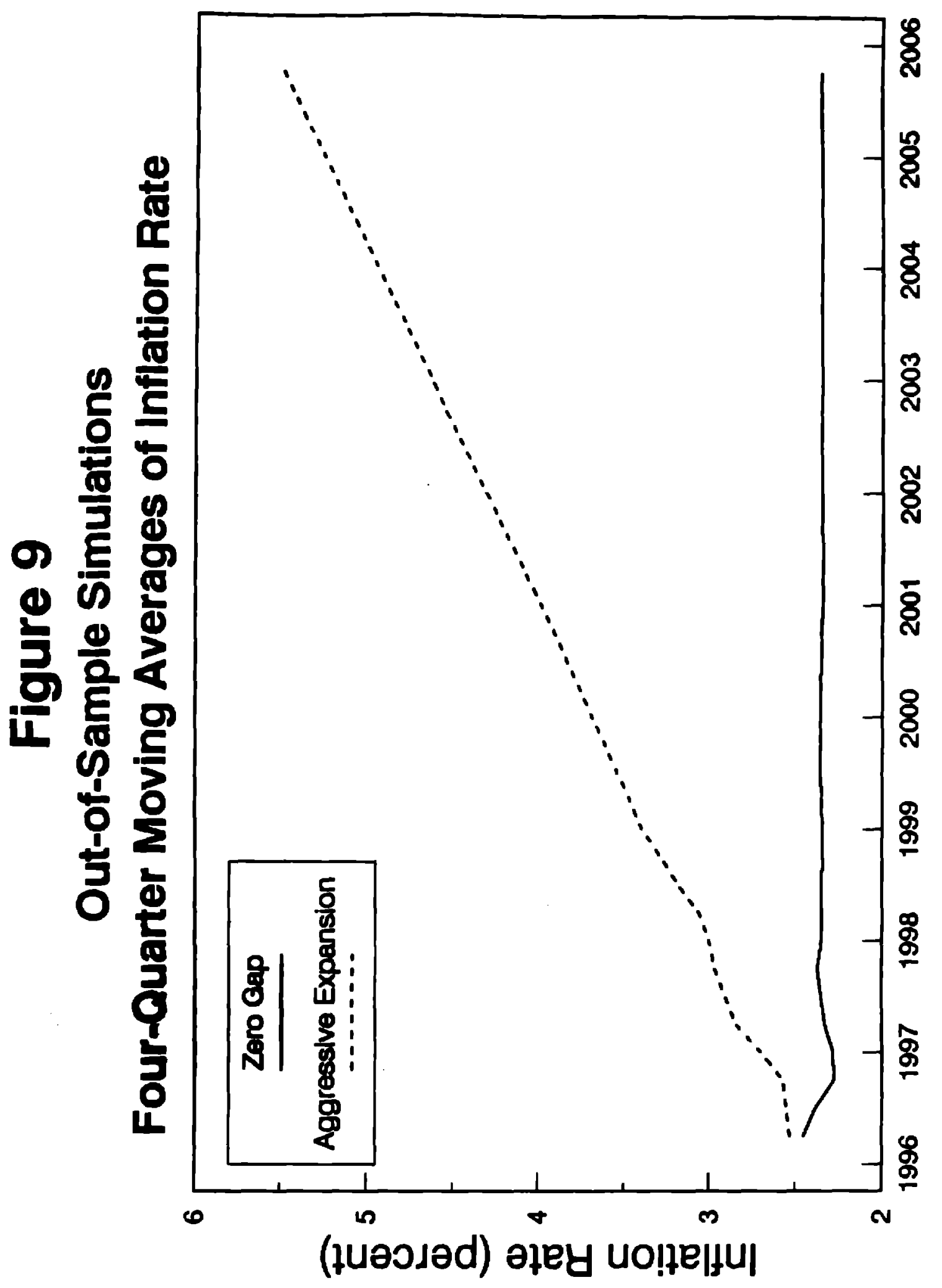

